\title{
Development and Decay Processes of Dual Inversion Layers in Winter over the Northwest Coast of the South China Sea
}

\author{
MASATO I. NODZU \\ Department of Geography, Tokyo Metropolitan University, Hachioji, Tokyo, and Department of Environmental Geochemical Cycle \\ Research, Japan Agency for Marine-Earth Science and Technology, Yokohama, Kanagawa, Japan \\ SHIN-YA OGINO \\ Department of Coupled Ocean-Atmosphere-Land Processes Research, Japan Agency for Marine-Earth Science and Technology, \\ Yokosuka, Kanagawa, Japan

\section{Jun Matsumoto} \\ Department of Geography, Tokyo Metropolitan University, Hachioji, Tokyo, and Department of Coupled Ocean-Atmosphere-Land \\ Processes Research, Japan Agency for Marine-Earth Science and Technology, Yokosuka, Kanagawa, Japan
}

(Manuscript received 23 December 2016, in final form 5 October 2017)

\begin{abstract}
Inversion layers in the lower troposphere appear centered at two heights, 1.5 and $4 \mathrm{~km}$, over the northwestern coast of the South China Sea in late boreal winter. The mechanisms of these dual inversion layers are investigated with thermal budget and composite analyses of the JRA-55 dataset. The thermal budget analysis classifies inversion layers between the levels of 700 and $600 \mathrm{hPa}$ into two types. One type is related to high pressure moving southward along the eastern edge of the Tibetan Plateau; the arrival of the high coincides with subsidence that warms the $600-\mathrm{hPa}$ level more strongly, and the stability increases between the 700 - and $600-\mathrm{hPa}$ levels. The other type is related to a synoptic-scale eastward-propagating wave in the upper troposphere. The upper-level high pressure in the wave is accompanied by a midtropospheric warm area whose intrusion at the $600-\mathrm{hPa}$ level generates the inversion layers. Inversions between the levels of 925 and $850 \mathrm{hPa}$ are related to heating and cooling by horizontal advection of potential temperature in the upper and lower levels, respectively. The vertical contrast of horizontal advection corresponds to a frontlike structure at the southern edge of a pressure surge. The pressure surge has a similar structure with the high pressure moving along the plateau edge as mentioned for the former type of inversion layers between the 700- and 600-hPa levels.
\end{abstract}

\section{Introduction}

Temperature inversion layers frequently appear in boreal winter in the lower and middle troposphere away from the surface over Indochina. Three types of seasonheight distribution were recognized in this region (Nodzu et al. 2006). In the southern region adjacent to the Malay Peninsula, inversion layers frequently occur at 2-km height during the winter. The frequent occurrence height increases from 2 to $5 \mathrm{~km}$ in the inland region of Indochina. Over the coastal region along the northern part of the South China Sea (SCS), inversion layers are also concentrated at around $1.5 \mathrm{~km}$ from January to March, below the height observed over the

Corresponding author: Masato I. Nodzu, nodzum@tmu.ac.jp inland of Indochina. There appear to be climatologically dual inversion layers, one above the other. The lower of the dual inversion layers has a larger vertical gradient of potential temperature than that of typical stable layers observed over the subtropical and tropical oceans (Johnson et al. 1999). Such a climatologically dual inversion layer structure plays an important role in chemical transport and convective activity. Relationships between air pollutants and a boundary layer structure including a stable layer such as an inversion layer have been investigated in many studies (e.g., Fehsenfeld et al. 1983; Wallace and Kanaroglou 2009). In recent years, three-dimensional observations (e.g., Kanaya et al. 2014), chemical model simulations (e.g., Goto et al. 2016), and their combined studies (e.g., Boersma et al. 2011) for the pollutants have been 
developed; therefore, it can be expected that the investigations will make great progress in understanding the structural relationship between the inversion layers and the pollutants. It is also known that inversion layers influence the development of a boundary layer as a precursor of daytime convection (e.g., Müller and Whiteman 1988). Recent development in boundary layer research is especially seen in the observational study in fine temporal and spatial resolution using boundary layer radar (Fukao and Hamazu 2014) and the numerical studies like a large-eddy simulation (e.g., Nakanishi et al. 2014). Outcomes from the studies in these fields including an inversion layer will give a comprehensive understanding of interaction between thermal structure and chemical distribution. A recent study based on sonde observations by Ogino et al. (2013) identified a local vertical maximum of ozone ratio at about $3 \mathrm{~km}$ in March at Hanoi in the northwestern coastal region of the South China Sea. This height corresponds to a layer where unstable layers frequently occur between the dual inversion layers found by Nodzu et al. (2006) as mentioned above. These observational results are therefore an example of the influence of the dual inversion layers on a chemical compound either directly by dynamical transport or indirectly by chemical reactions.

Nodzu et al. (2011) examined the development and decay processes of stable layers with thermal terms causing potential temperature tendency for a case over the inland region of Indochina. However, their study did not extend to the northwestern coastal region of the South China Sea. In the present study, the development and decay processes of inversion layers are investigated by focusing on potential temperature tendency with the same method as Nodzu et al. (2011). Moreover, we use a modified method on the tendency and comprehensive analyses of meteorological fields over the Asian continent causing changes in the thermal terms in order to discuss their mechanisms.

The remainder of this paper is organized as follows. The data and methodology are presented in section 2, and the results of thermal terms making inversion layers are described in section 3. The development and decay of inversion layers is discussed based on composited spatial distributions of physical quantities in section 4 . Finally, the conclusions are presented in section 5.

\section{Data and method}

We examine the thermal budget and physical quantity fields related to inversion layer development and decay using the objective reanalysis data JRA-55 (Kobayashi et al. 2015; Harada et al. 2016) at the standard pressure levels. We use the $1.25^{\circ}$ latitude-longitude gridded version of JRA-55. Spectral TL319 is the original horizontal resolution of the model used in the operational data assimilation system producing the JRA-55 dataset. The spectral resolution of TL319 corresponds to about $60-\mathrm{km}$ resolution in the subtropics. The $1.25^{\circ}$ latitudelongitude or $60-\mathrm{km}$ horizontal resolution is high enough to analyze inversion layers in the present study judging from the horizontal distribution of the same type of seasonal and vertical change in inversion layer frequency shown by Nodzu et al. (2006). The analysis period is the $29 \mathrm{yr}$ from 1979 to 2007 . It is noteworthy that we can obtain the results leading the same conclusions by the analysis with the JRA-25 (Onogi et al. 2007), the formerversion reanalysis JRA-55 dataset.

In this study, we focus on the static stability of an inversion layer. Stability is defined as the vertical gradient of potential temperature $\partial \theta / \partial z$ in a layer between the standard pressure levels adopted by the reanalysis data. In this study, an inversion layer is reinterpreted as a statically stable layer with a relatively large stability. Therefore, we do not limit the meaning of an inversion layer to a layer with a vertically positive temperature gradient. Furthermore, the development (decay) period of an inversion layer is interpreted as a period with a positive (negative) stability tendency. The stability tendency can be transformed as follows:

$$
\frac{\partial}{\partial t}\left(\frac{\partial \bar{\theta}}{\partial z}\right) \simeq \frac{\partial}{\partial z}\left(\frac{\partial \bar{\theta}}{\partial t}\right)
$$

where $\theta$ is potential temperature and for a given variable $A, \bar{A}$ denotes horizontal regional means of $A$. Note that we interpret grid values in the reanalysis data as $\bar{A}$. Therefore, the stability tendency can be understood by considering the $\theta$ tendency $\partial \bar{\theta} / \partial t$ in the upper and lower levels. The $\theta$ tendency can be expressed as follows:

$$
\begin{aligned}
& \frac{\partial \bar{\theta}}{\partial t}=\left(-\bar{u} \frac{\partial \bar{\theta}}{\partial x}-\bar{v} \frac{\partial \bar{\theta}}{\partial y}\right)+\left(-\bar{\omega} \frac{\partial \bar{\theta}}{\partial p}\right)+Q_{1} \text { and } \\
& Q_{1}=-\frac{\partial \overline{\left(\theta^{\prime} \omega^{\prime}\right)}}{\partial p}-\left(\frac{p_{0}}{p}\right)^{R / C_{p}} \frac{L}{C_{p}} \frac{D \bar{q}}{D t}+\left(\frac{p_{0}}{p}\right)^{R / C_{p}} \frac{\bar{R}}{C_{p}}
\end{aligned}
$$

where $u, v, \omega, Q_{1}, q$, and $R$ are the zonal wind, meridional wind, vertical $p$ velocity, modified apparent heat source, water vapor mixing ratio, and radiative cooling and heating; and $A^{\prime}=A-\bar{A}$, represents the deviation from the regional mean. The apparent heat source is modified from the original definition presented by Yanai et al. (1973) with the term $\left(p_{0} / p\right)^{R / C_{p}}$ fitted by considering the $\theta$ tendency. We used the modified apparent moisture sink $Q_{2}$, also introduced by Yanai et al. (1973), in the same manner as $Q_{1}$. We note that discussion including $Q_{1}$ and/or $Q_{2}$ has relatively lower accuracy than the 


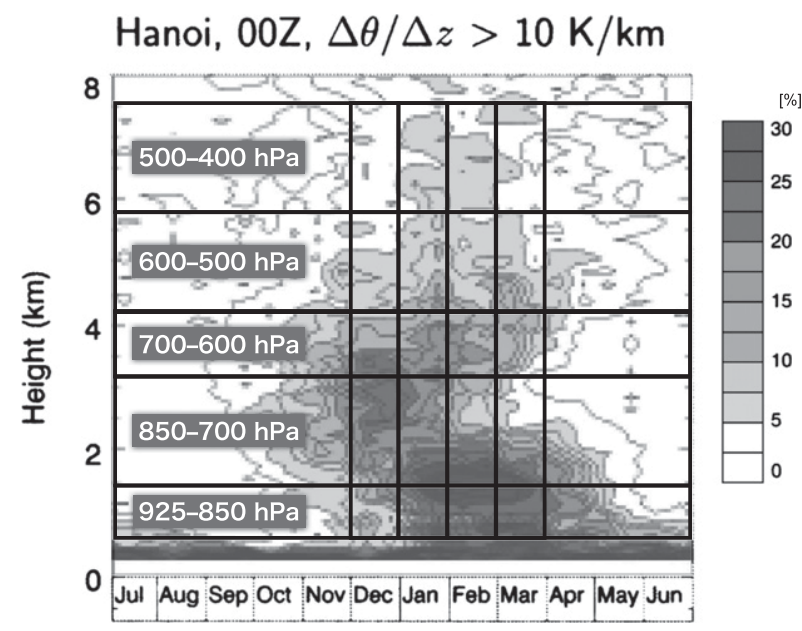

FIG. 1. Time-height cross section of inversion layer frequency (\%) at $0000 \mathrm{UTC}\left(0700\right.$ local time) for Hanoi $\left(21.01^{\circ} \mathrm{N}, 105.80^{\circ} \mathrm{E}\right)$, from Fig. 10c of Nodzu et al. (2006). The frequency is defined as a ratio of the observed number of stability conditions, $\partial \theta / \partial z>$ $10 \mathrm{~K} \mathrm{~km}^{-1}$, to the number of all the observations in the operational rawinsonde dataset and calculated every $100 \mathrm{~m}$ with interpolated temperature from the data at the recorded significant and mandatory levels. The horizontal axis is from July to June to cover the entire boreal winter. The horizontal and vertical thick lines are superposed to show the layer and month divisions used in the analyses of the present study.

other values because of the low reliability caused by the uncertainty of the model producing JRA-55 and artificial source or sink introduced into the water budget through the modification by observations (Kobayashi et al. 2015). The first and second parenthesized terms of the right-hand side of Eq. (2) show horizontal and vertical advection of $\theta$. The third term $Q_{1}$ is a residual component that consists of vertical eddy flux divergence of $\theta$, latent heat release and/or absorption, and radiative cooling and/or heating as shown in Eq. (3). The last two terms in Eq. (3) are modified by fitting, considering the $\partial \bar{\theta} / \partial t$. Our analysis and discussion involve contributions to the $\theta$ tendency by the three terms horizontal advection of $\theta$ (HA), vertical advection of $\theta(\mathrm{VA})$, and $Q_{1}$ shown in Eq. (2). We refer to these three terms as thermal factors.

We select the horizontal grid point of $21.25^{\circ} \mathrm{N}$, $106.25^{\circ} \mathrm{E}$ for defining temperature inversion events. This point is closest to Hanoi aerological station $\left(21.01^{\circ} \mathrm{N}\right.$, $105.80^{\circ} \mathrm{E}$ ) and is representative of the region with vertical dual inversion layers in the climatology, as shown by Nodzu et al. (2006). We selected two typical pressure layers and months for detailed analyses from the frequency distribution of inversion layers plotted against month and height (Fig. 1). The lower layer is between the 925- and 850-hPa levels from January to March, and the upper layer is between the 700- and 600-hPa levels in
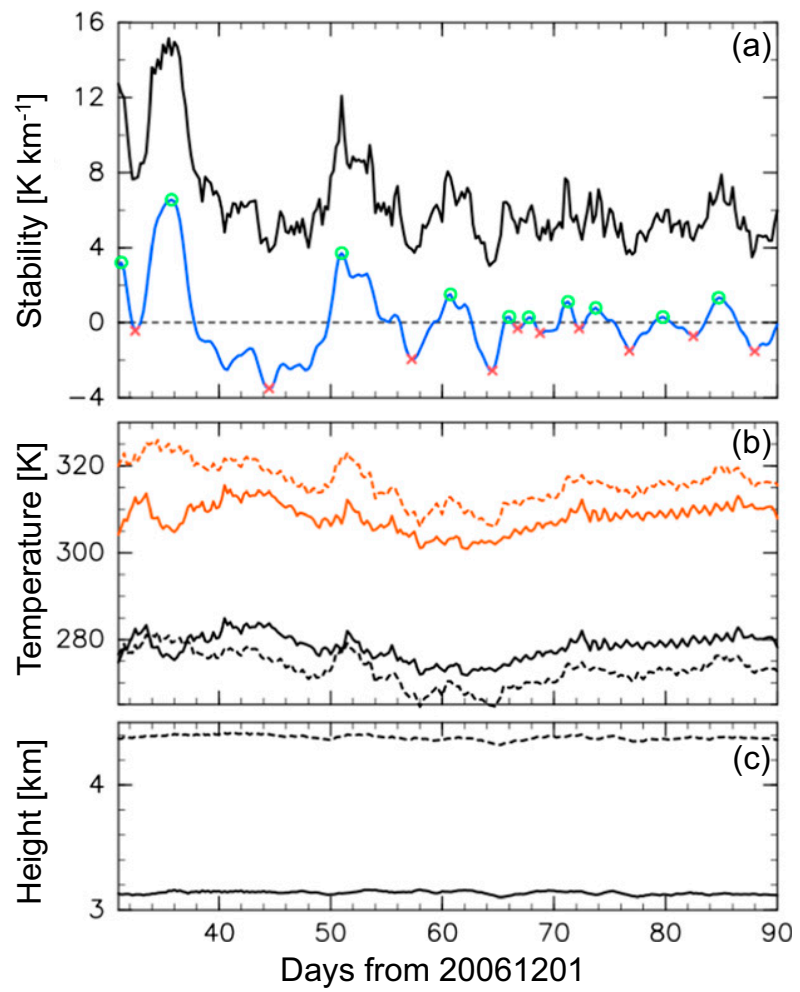

FIG. 2. A sample of inversion layers in January and February in 2007 between 700 and $600 \mathrm{hPa}$ at $21.25^{\circ} \mathrm{N}, 106.25^{\circ} \mathrm{E}$. Time series of (a) stability (black) and filtered stability (blue) in the layer between 700 and $600 \mathrm{hPa}$, (b) temperature at 700 (black solid curve) and $600 \mathrm{hPa}$ (black dashed curve) and potential temperature at 700 (orange solid curve) and $600 \mathrm{hPa}$ (orange dashed curve), and (c) geopotential height at 700 (solid curve) and $600 \mathrm{hPa}$ (dashed curve). The stability maxima of an inversion layer event and the local minima are shown in (a) with green circles and red crosses respectively.

January and February. We classify the latter type of inversion layers with the thermal factor giving the largest contribution to the inversion layer development. Moreover, we analyze and discuss the thermal factors and their contributions to the $\theta$ tendency by composite analysis. The analysis and discussion concerning the inversion layers between the $925-$ and $850-\mathrm{hPa}$ levels are limited to the relationship between $\partial \bar{\theta} / \partial t$ and horizontal advection of $\theta$ considering the poor reliability of the vertical velocity in the reanalysis data in the boundary layer. We do not use vertical advection of $\theta$ and $Q_{1}$ in any analyses on this type of inversion layers and, in consequence, we do not classify them as done for the inversion layers between the 700- and 600-hPa levels.

We begin to repeat that the stability is the vertical gradient of potential temperature $\partial \theta / \partial z$ in a layer between the standard pressure levels in the present study for the definition of an inversion layer event. A simple time series of stability is filtered over a time-scale range 
TABLE 1. Number of inversion layers for each month, layer, and DTF from December to March between 850 and $400 \mathrm{hPa}$ at $21.25^{\circ} \mathrm{N}$, $106.25^{\circ} \mathrm{E}$ from 1979 to 2007 , together with the climatological mean stability of the layer (clim stbl) and contribution to the mean (contr). The unit for the stability and the contribution is $\mathrm{K} \mathrm{km}^{-1}$. Inversion layers are classified by their DTF into those whose DTFs are due to HA and VA, and apparent heat source $Q_{1}$. Contribution to the mean is defined with stability values 1 day before and after the maximum stability time in each inversion layer event.

\begin{tabular}{|c|c|c|c|c|c|c|c|c|c|c|c|c|c|}
\hline \multicolumn{2}{|l|}{ Month } & \multicolumn{3}{|c|}{ December } & \multicolumn{3}{|c|}{ January } & \multicolumn{3}{|c|}{ February } & \multicolumn{3}{|c|}{ March } \\
\hline Layer & DTF & Count & Contr & Clim stbl & Count & Contr & Clim stbl & Count & Contr & Clim stbl & Count & Contr & Clim stbl \\
\hline \multirow[t]{3}{*}{$500-400 \mathrm{hPa}$} & HA & 36 & 0.04 & 4.35 & 72 & 0.13 & 4.42 & 56 & 0.11 & 4.49 & 59 & 0.08 & 4.28 \\
\hline & VA & 43 & 0.05 & & 43 & 0.04 & & 35 & 0.05 & & 37 & 0.03 & \\
\hline & $Q_{1}$ & 22 & 0.04 & & 13 & 0.04 & & 12 & 0.01 & & 26 & 0.01 & \\
\hline \multirow[t]{3}{*}{$600-500 \mathrm{hPa}$} & HA & 52 & 0.04 & 4.71 & 75 & 0.08 & 5.07 & 49 & 0.06 & 4.98 & 52 & 0.06 & 4.69 \\
\hline & VA & 34 & 0.04 & & 33 & 0.04 & & 28 & 0.05 & & 33 & 0.02 & \\
\hline & $Q_{1}$ & 27 & 0.04 & & 22 & 0.04 & & 40 & 0.04 & & 48 & 0.04 & \\
\hline \multirow[t]{3}{*}{$700-600 \mathrm{hPa}$} & HA & 16 & 0.00 & 6.76 & 29 & 0.03 & 6.21 & 39 & 0.05 & 5.50 & 36 & 0.05 & 4.64 \\
\hline & VA & 48 & 0.04 & & 50 & 0.07 & & 41 & 0.06 & & 45 & 0.03 & \\
\hline & $Q_{1}$ & 70 & 0.12 & & 48 & 0.11 & & 48 & 0.07 & & 61 & 0.04 & \\
\hline \multirow[t]{3}{*}{$850-700 \mathrm{hPa}$} & HA & 7 & 0.01 & 7.42 & 10 & 0.01 & 7.49 & 4 & 0.01 & 6.85 & 7 & 0.03 & 6.16 \\
\hline & VA & 73 & 0.08 & & 108 & 0.15 & & 88 & 0.18 & & 94 & 0.17 & \\
\hline & $Q_{1}$ & 6 & 0.01 & & 4 & 0.00 & & 5 & 0.01 & & 4 & 0.00 & \\
\hline
\end{tabular}

from 2 to 60 days (Fig. 2). The following definitions concerning inversion layers are based on the filtered stability. An inversion layer event is defined as a period with positive stability over three consecutive time steps $(18 \mathrm{~h})$ in the 6-hourly reanalysis data. A stability maximum in an inversion layer event is defined as the local maximum within the inversion layer event. The development period of an inversion layer is defined as the period from the time of a local stability minimum within the noninversion layer period to the time of maximum stability in the subsequent inversion layer event.

The inversions between the $700-$ and $600-\mathrm{hPa}$ levels are classified using the vertical structure of the three thermal factors in Eq. (2) following Nodzu et al. (2011). We define the dominant thermal factor (DTF) as the greatest contributor to the inversion layer development among the vertical differences of horizontal advection of $\theta$, vertical advection of $\theta$, and $Q_{1}$.

Composite analysis was employed to investigate the mechanisms related to inversion layer development, with composites centered around the time of the stability maximum of inversion layers. We analyzed composited features of the three thermal factors-the $\partial \bar{\theta} / \partial t$, humidity, and the stability anomaly in time-height cross sections-and the horizontal advection of $\theta$, vertical advection of $\theta$, horizontal winds, vertical velocity, and anomalies of horizontal winds and geopotential height in horizontal maps. In addition, latitude-height cross sections were composited with anomalies of horizontal winds and geopotential height. Unless stated otherwise, anomalies were calculated with respect to the climatological values.

\section{Thermal budget analyses}

\section{a. Dominant thermal factors of inversion layers}

We begin by describing the relative importance on dominant thermal factors for inversion layers for each month and layer in Table 1 . The months and layers correspond to the 16 rectangular boxes shown in Fig. 1 from December to March between the levels of 850 and $400 \mathrm{hPa}$.

Inversion layers whose dominant thermal factor is vertical advection of $\theta$ are dominant in the $850-700-\mathrm{hPa}$ layer, making up about $80 \%$ of the inversion layers. This type of inversion increases the climatological mean stability (CMS) by at least $0.08 \mathrm{~K} \mathrm{~km}^{-1}$ in each month, and their contribution overwhelms those of other dominant thermal factors. Thus, in this layer, the dominant thermal factor of typical inversion layers is vertical advection of $\theta$, in terms of both frequency and effect on the climatological mean stability.

In the layers above the 700-hPa level, the composition of inversion layers in terms of dominant thermal factors is mixed and there are no overall dominant thermal factors. Inversion layers whose dominant thermal factor is $Q_{1}$ except in January has the largest count among dominant thermal factors in the layer between the levels of 700 and $600 \mathrm{hPa}$. Such a situation can be observed in the contributions to the climatological mean stability except in March.

The most important dominant thermal factor is horizontal advection of $\theta$ for inversion layers above the 600 $\mathrm{hPa}$ level except in December. Inversion layers whose thermal factor is vertical advection show the largest count and contribution to the climatological mean stability in December for inversion layers in the layer between the 500- and 400-hPa levels. 
The above results show that in the layer between the levels of 850 and $700 \mathrm{hPa}$, vertical advection of $\theta$ is the major process generating inversion layers for the climatology in the northwestern coast of the South China Sea. However, there is not such a clearly major process for inversion layers in the layer between the $700-$ and $600-\mathrm{hPa}$ levels from January to March and above the 600-hPa level in December. The relatively major dominant thermal factor is $Q_{1}$ and horizontal advection in the $700-600-\mathrm{hPa}$ layer in December and above the 600-hPa level from January to March.

\section{b. Time-height distribution of thermal factors and potential temperature tendency for inversion layers in the higher layer}

We will examine time-height cross sections of thermal factors and potential temperature tendency composited for development events of the inversion layers between the 700- and 600-hPa levels. In this subsection, the description of results aims at identifying common features in each month and for each dominant thermal factor.

Figures 3 and 4 show time-height cross sections of $\theta$ tendency, vertical advection of $\theta$, horizontal advection of $\theta$, and $Q_{1}$ in January and February, respectively. Two types of patterns can be recognized in the sections of $\theta$ tendency. The first is a four-leaf-clover pattern in the sections for inversions whose dominant thermal factor is $Q_{1}$ in February. The pattern consists of cooling in the lower levels below $700 \mathrm{hPa}$ and warming between the 600- and $400-\mathrm{hPa}$ levels before the stability maximum is reached, and vice versa afterward. The second is an inverted percent mark pattern in the other sections. The pattern has a more emphasized heating area moving downward almost without division by cooling area. In February, the sections show a pattern somewhat close to the four-leaf-clover pattern. Both $\theta$ tendency patterns were conspicuous within two days of the stability maximum, over a shorter period than the typical development and decay period of the inversion layers in this layer. Both patterns are consistent with the development and decay of stable layers.

Vertical advection is generally negative except in parts of higher levels. It generally increases with height above the $600-\mathrm{hPa}$ level except the case of inversion layers whose dominant thermal factor is $Q_{1}$ in February. Especially in the cases of inversion layers whose dominant thermal factor is horizontal or vertical advection, a stable area moved downward from the 400- to the 700-hPa levels for 4 days before the stability maximum. In the cases of inversion layers whose dominant thermal factor is vertical advection, the upward gradient of vertical advection was found in January and February before the stability maximum between the levels of 700 and $600 \mathrm{hPa}$. However, in February the upward gradient is unclear between the $600-$ and $400-\mathrm{hPa}$ levels from $T_{\text {smax }}-4.0$ to -2.0 [writing $T_{\text {smax }}-(+) i$ to indicate $i$ days before (after) the stability maximum]. A common feature seen in the cases of inversion layers whose dominant thermal factor is vertical advection and $Q_{1}$ was a vertically deep area of positive vertical advection that existed above the 500-hPa level before the stability maximum in January and February. The positive vertical advection in the deep layer weakened soon except in the cases of inversion layers whose dominant thermal factor is vertical advection in January. Such a deep area with positive vertical advection is not seen in the cases of inversion layers whose dominant thermal factor is horizontal advection. It is worth describing the negative vertical advection centered around the $850-\mathrm{hPa}$ level; however, attention should be paid to the possibility that the reanalysis data did not fully reproduce the vertical velocity in the boundary layer.

Overall, horizontal advection is positive in the troposphere and strongly positive especially between the 900- and 750-hPa levels. In the case of inversion layers whose dominant thermal factor is horizontal advection, the most important feature observed in the horizontal advection pattern is areas greater than $2 \mathrm{Kday}^{-1}$ appeared between the 650- and 400-hPa levels just above the inversion layers. In February, the area appears in a broader layer expanding upward than in January. It continues at least from $T_{\mathrm{smax}}-5.0$ and is accompanied by a continuous stable area with $\partial \bar{\theta} / \partial z$ larger than $0.2 \mathrm{~K} \mathrm{~km}^{-1}$ from $T_{\text {smax }}-4.0$ both in January and February. The area of higher horizontal advection is also accompanied by negative or slightly positive horizontal advection at $700 \mathrm{hPa}$. This vertical pattern is consistent with that of $\theta$ tendency and the inversion layer development. However, the pattern is inconsistent for the cases of the inversion layers whose dominant thermal factors are vertical advection and $Q_{1}$. In these cases, the smaller horizontal advection is observed at $650-$ and 600-hPa levels compared with the layer between the 850and $700-\mathrm{hPa}$ levels. The horizontal advection is obviously negative especially in the case of the inversion layers whose dominant thermal factor is vertical advection. Thus, the vertical pattern of horizontal advection is not responsible for generating the inversion layer.

The $Q_{1}$ has generally smaller values at the $700-\mathrm{hPa}$ level, in contrast to larger values in the layer between the 600- and 400-hPa levels. The sections share an area of stronger negative $Q_{1}\left(<-2 \mathrm{~K} \mathrm{day}^{-1}\right)$ at the $700-\mathrm{hPa}$ level just below the stability maximum in all the cases. The area of negative $Q_{1}$ is clearer in the cases of inversion layers whose dominant thermal factors are $Q_{1}$ and vertical advection in January than in the other cases. 

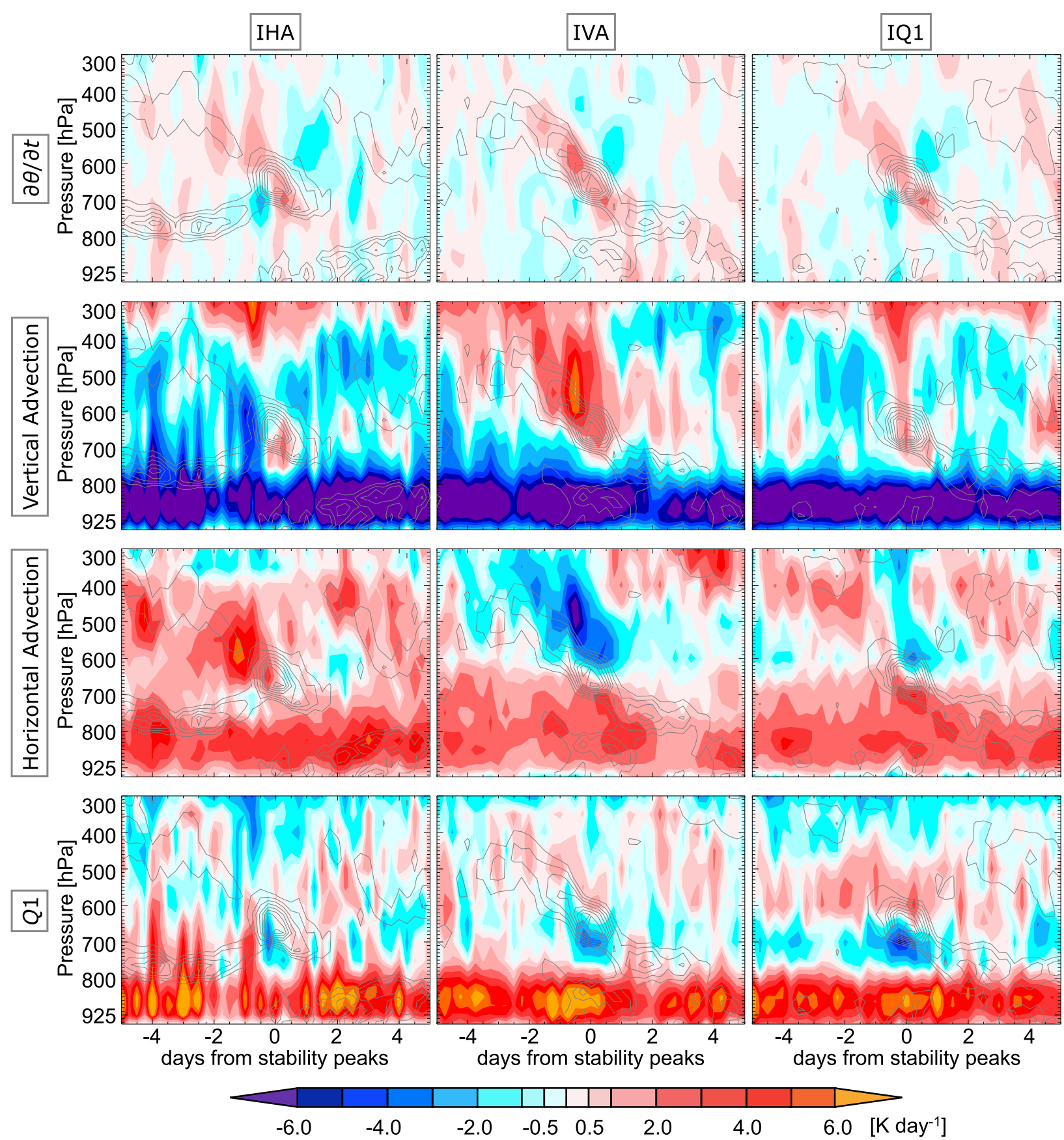

FIG. 3. Composite time-height cross sections of thermal terms for inversion layers whose dominant thermal factors are (left) horizontal advection of $\theta$, (center) vertical advection of $\theta$, and (right) $Q_{1}$ in the 700-600-hPa layer over the northwestern coastal region of the South China Sea $\left(21.25^{\circ} \mathrm{N}, 106.25^{\circ} \mathrm{E}\right)$ in January. Shown are (top)-(bottom) potential temperature tendency $\partial \theta / \partial t$, vertical and horizontal advection of $\theta$, and apparent heat source $Q_{1}\left(\mathrm{~K} \mathrm{day}^{-1}\right)$. The composite is calculated over 10 days centered on the time of maximum stability in the 700-600-hPa layer for the inversion layer events. Gray thin contours (interval $0.3 \mathrm{~K} \mathrm{~km}^{-1}$ ) show composite stability starting at values of $0.2 \mathrm{~K} \mathrm{~km}^{-1}$.

Sections of moisture sink $Q_{2}$ are shown in Fig. 5. Negative values were seen around the 700 -hPa level corresponding to the stronger negative $Q_{1}$ areas of $<-2 \mathrm{~K} \mathrm{day}^{-1}$ in the cases of inversion layers whose dominant thermal factors are $Q_{1}$ and vertical advection in January. An unclear minimum of $Q_{2}$ can be recognized at the $700-\mathrm{hPa}$ level in the case of inversion layers whose dominant thermal factors are vertical advection and $Q_{1}$ in February. On 

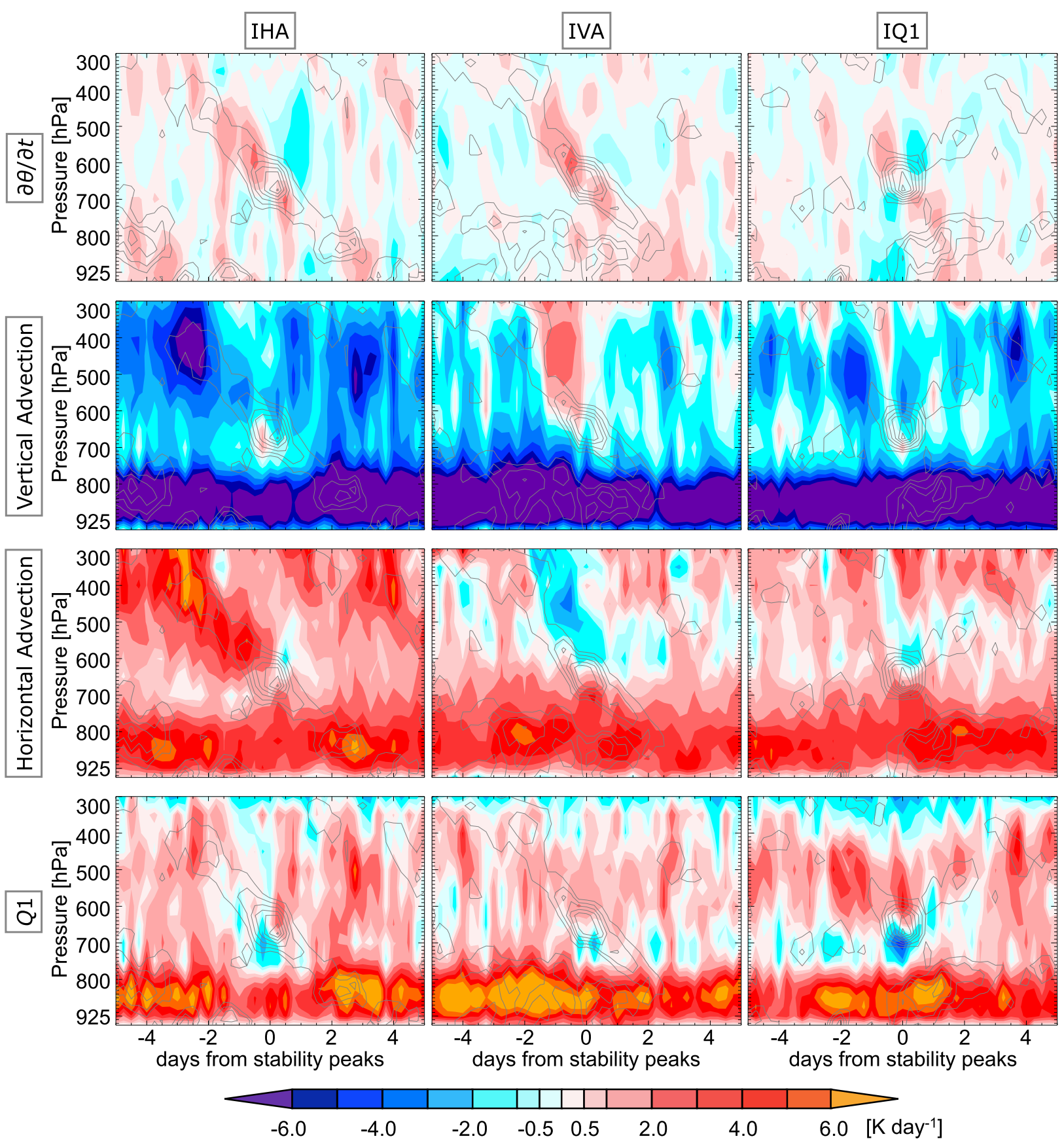

FIG. 4. As in Fig. 3, but for February.

the other hand, clear negative areas of $Q_{2}$ cannot be observed in the case of inversion layers whose dominant thermal factor is horizontal advection.

The time-height distribution of thermal factors can be roughly classified into two groups: one includes that seen in the cases of inversion layers whose thermal factors are vertical advection and $Q_{1}$ where there is a vertically continuous area of positive vertical advection above the
500-hPa level before the stability maximum; the other corresponds to that seen in the case of inversion layers whose thermal factor is horizontal advection where there is an area of horizontal advection larger than $2 \mathrm{~K} \mathrm{day}^{-1}$ between 600 and $500 \mathrm{hPa}$ from $T_{\text {smax }}-2.0$ to -0.5 and an area of negative or slightly positive horizontal advection. Figure 6 shows the merged sections of $\theta$ tendency, thermal factors, and $Q_{2}$ composited for the 

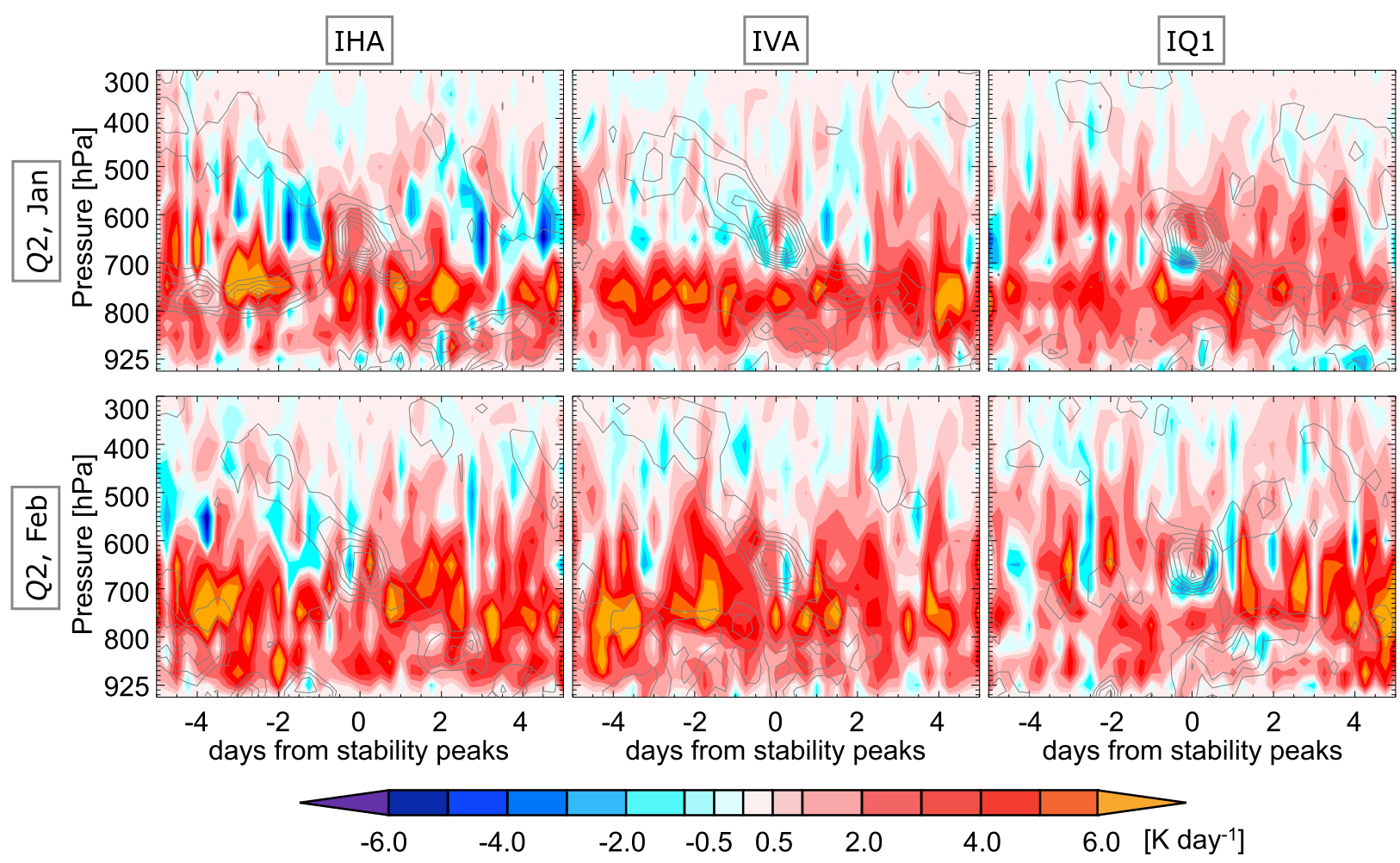

FIG. 5. As in Fig. 3, but for apparent moisture sink $Q_{2}$ in (top) January and (bottom) February.

cases of inversion layers whose dominant thermal factors are vertical advection and $Q_{1}$ in January and February, for the discussion in the following section. In the merged section of vertical advection (Fig. 6b), an area with VA larger than $1 \mathrm{~K}$ day $^{-1}$ clearly emerges above the $600-\mathrm{hPa}$ level between $T_{\text {smax }}-0.5$ and $T_{\text {smax }}$.

\section{c. Time-height distribution of horizontal advection and temperature tendency on inversion layers in the lower layer}

In this subsection we show composited features of horizontal advection of $\theta$ and $\theta$ tendency in time-height cross sections without classification by dominant thermal factors in order to discuss contribution of horizontal advection to the development of the inversion layers in the layer between the levels of 925 and $850 \mathrm{hPa}$. Composited events have mean stability stronger than $10 \mathrm{~K} \mathrm{~km}^{-1}$ one day before and after the stability maximum. We will show sections composited over January, February, and March because of common characteristics in the three months.

Figure 7 shows a time-height cross section of $\theta$ tendency. Stability begins increasing at the level below $850 \mathrm{hPa}$ when the $\theta$ tendency decreases lower than $-3 \mathrm{Kday}^{-1}$ from $T_{\text {smax }}-1.5$. The $\theta$ tendency then becomes positive after the stability maximum is achieved. The $\theta$ decrease is strongest at $925 \mathrm{hPa}$, and therefore the stability strengthens in the layer between the levels of 925 and $850 \mathrm{hPa}$. The opposite process occurs after the stability maximum is reached. The horizontal advection section shows that the advection is positive at almost all levels in the period between $T_{\text {smax }}-1.5$ and $T_{\text {smax }}+1.5$ when the $\theta$ tendency conspicuously decreases and increases especially below the $850-\mathrm{hPa}$ level. Heating by the horizontal advection is strongest at the $850-\mathrm{hPa}$ level. On the other hand, there is a period of weak heating and cooling at the 925-hPa level before the stability maximum. The peak of $\theta$ decrease occurs at $T_{\text {smax }}-0.75$ and coincides with negative horizontal advection at the $925-\mathrm{hPa}$ level. On the other hand, the horizontal advection heating revives at $T_{\text {smax }}-0.5$ at the $925-\mathrm{hPa}$ level. The $\theta$ tendency begins to increase at the same time. Therefore, the temporal evolution of the $\theta$ tendency is contributed by that of the horizontal advection before and after the stability maximum. In other words, the temporal evolution of horizontal advection might play a role in that of the $\theta$ tendency and, consequently, the development and decay of the inversion layers.

\section{Spatial distribution composite}

In this section, we examine and discuss the horizontal fields causing stable layers using composite analysis in order to understand the results obtained from the 

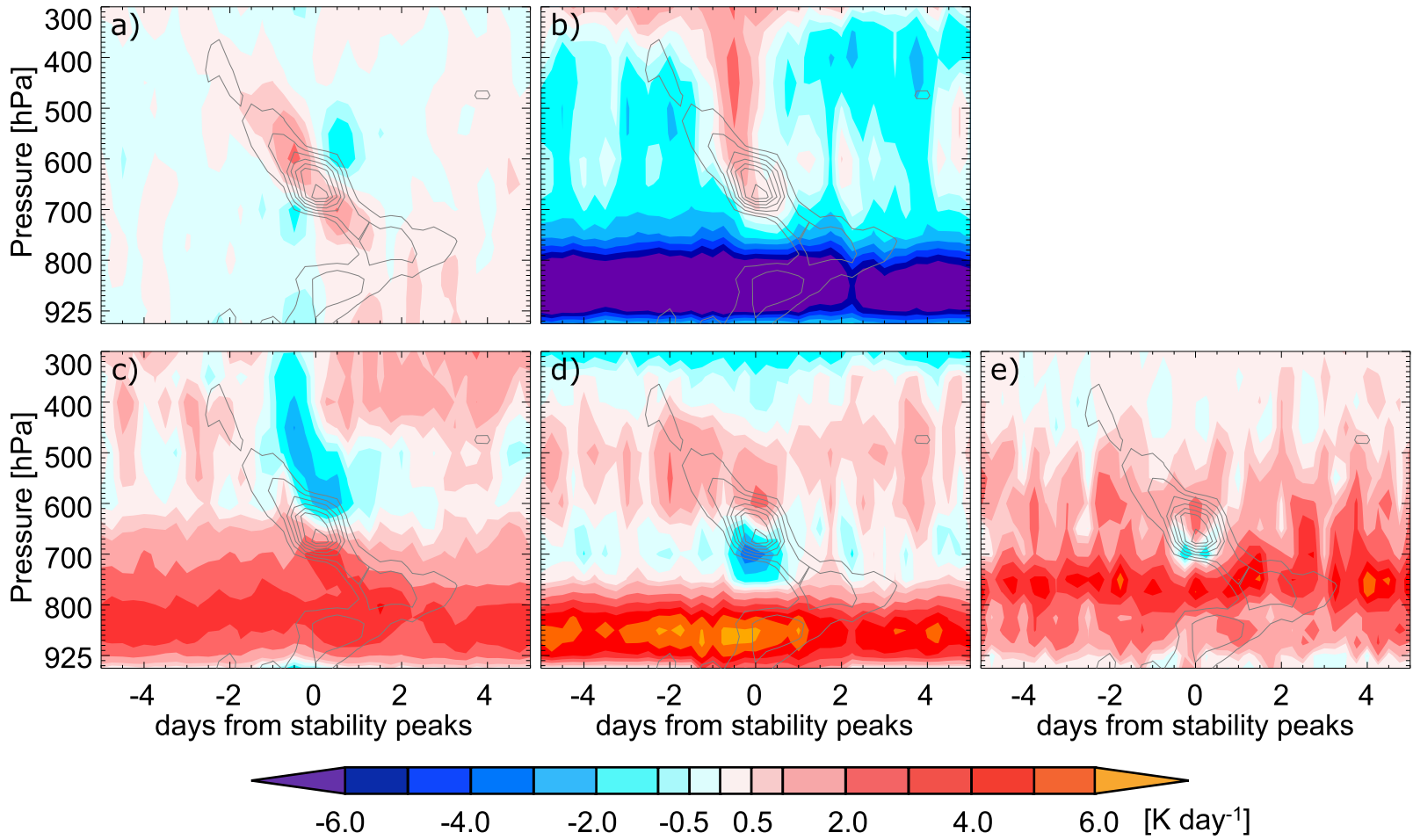

FIG. 6. Time-height cross sections of thermal budget terms $\left(\mathrm{K}\right.$ day $\left.^{-1}\right)$ : (a) potential temperature tendency $\partial \theta / \partial t$, (b) vertical advection, (c) horizontal advection, (d) apparent heat source $Q_{1}$, and (e) apparent moisture sink $Q_{2}$, calculated for inversion layers whose dominant thermal factor is vertical advection or $Q_{1}$ in the 700-600-hPa layer in January and February. Gray thin contours (interval $0.3 \mathrm{~K} \mathrm{~km}{ }^{-1}$ ) show composite stability starting at values of $0.2 \mathrm{~K} \mathrm{~km}^{-1}$.

time-height cross sections of the thermal factors and the potential temperature tendency in the previous section from the large-scale view.

\section{a. Inversion layers whose thermal factors are vertical advection and $Q_{1}$ in the layer between the levels of 700 and $600 \mathrm{hPa}$}

Following the previous section, inversion layers whose thermal factors are vertical advection of $\theta$ and $Q_{1}$ in the layer between the levels of 700 and $600 \mathrm{hPa}$ are shown in a merged composite analysis. Their common feature is the vertically continuous region of positive vertical advection of $\theta$ above the 500-hPa level before the stability maximum (Figs. 3, 4, and 6).

We first show a vertical advection horizontal map in Fig. 8. Two regions with large vertical advection are evident: one with subsidence heating around $T_{\text {smax }}-0.5$ at the $600-\mathrm{hPa}$ level corresponding to the upper-level heating; the other shows subsidence heating around $T_{\text {smax }}+0.25$ at the $700-\mathrm{hPa}$ level corresponding to the lower-level heating observed in Fig. 6. The former and the latter contribute to the development and the decay of the inversion layers, respectively. Stronger subsidence heating of over $2 \mathrm{~K} \mathrm{day}^{-1}$ covers northeastern Indochina and northern South China Sea from $T_{\text {smax }}-1.0$ (not shown) to $T_{\text {smax }}-0.5$ on the $600-\mathrm{hPa}$ surface. The region of stronger heating expands from the southeastern foot of the Tibetan Plateau at $T_{\text {smax }}-0.5$ and retreats toward the plateau at $T_{\text {smax }}-1.25$ and after $T_{\text {smax }}-0.25$. The peak of subsidence heating occurs later on the 700-hPa surface. A stronger subsidence heating region of over $2 \mathrm{~K} \mathrm{day}^{-1}$ is evident over the northern part of the South China Sea from $T_{\text {smax }}-0.5$ to +1.0 on this surface. This region intrudes onshore over the northwestern coast of the South China Sea at $T_{\text {smax }}+0.25$. We consider that the increase in positive vertical advection can be partly explained by the increase in the vertical gradient of $\theta$ in the upper layer between the levels of 700 and $600 \mathrm{hPa}$. It is implied that the temperature increase at the $700-\mathrm{hPa}$ level influences stability below the 700-hPa level except in the case of inversion layers whose thermal factor is $Q_{1}$ in February (Figs. 3 and 4). However, it should be noted that the subsidence of the inversion layers cannot be explained by a simple subsidence of the air judging from the relationship between the vertical velocity and the subsidence speed of the inversion layers.

Figure 9 shows geopotential height fields on the 700-hPa surface composited for the inversion layers 

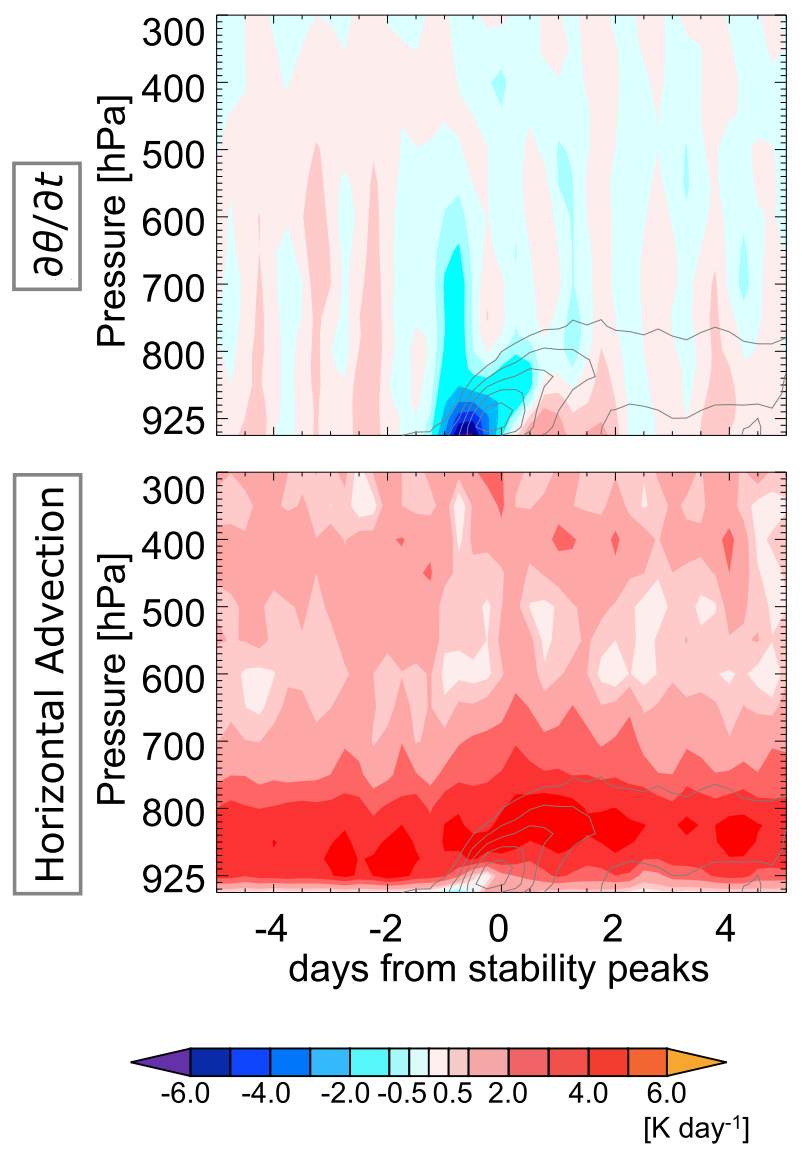

FIG. 7. Composite time-height cross sections of (top) potential temperature tendency $\partial \theta / \partial t$ and (bottom) horizontal advection of $\theta$ at $21.25^{\circ} \mathrm{N}, 106.25^{\circ} \mathrm{E}$ for inversion layers between 925 and $850 \mathrm{hPa}$ from January to March $\left(\mathrm{K} \mathrm{day}^{-1}\right)$. Composited events are limited to inversion layer events with mean stability $>10 \mathrm{~K} \mathrm{~km}^{-1}$ one day before and after the stability maximum. The composite is calculated in the same way as Fig. 3. Gray thin contours (interval $1.0 \mathrm{~K} \mathrm{~km}^{-1}$ ) show composite stability starting at values of $0.4 \mathrm{~K} \mathrm{~km}^{-1}$.

whose thermal factors are vertical advection of $\theta$ and $Q_{1}$ in January and February in the layer between the 700and $600-\mathrm{hPa}$ levels. Corresponding to the area of strongest subsidence at $T_{\text {smax }}-0.5$ shown in Fig. 8, a region of high pressure is located over the eastern foot of the Tibetan Plateau. This high is located farther north at $T_{\text {smax }}-1.25$, and it appears to be the southeastern part of the high pressure on the northern side of the plateau. It can be traced back to the Aral Sea area at $T_{\text {smax }}-4.0$. This high pressure can be related with strong subsidence at the 600 -hPa level at $T_{\text {smax }}-0.5$. The high pressure rapidly weakens at $T_{\text {smax }}+0.25$ and becomes difficult to detect at $T_{\text {smax }}+1.0$. The southward movement and rapid decay of the high pressure can be related with subsidence heating at the $600-\mathrm{hPa}$ level and generate a stable layer in the layer between the levels of 700 and $600 \mathrm{hPa}$ over a short period of about one day.
We have reported clear coincident temporary minima of $Q_{1}$ and $Q_{2}$ in the levels between 850 and $600 \mathrm{hPa}$ for the cases of inversion layers whose dominant thermal factors are vertical advection of $\theta$ and $Q_{1}$ in January (Figs. 3 and 5). Less evident minima are also seen in February (Fig. 4). Particularly in the case of inversion layers whose dominant thermal factor is $Q_{1}$, the cooling by $Q_{1}$ contributed to the decrease of $\theta$ in the lower level of the stable layers before the time of the stability maximum. Nodzu et al. (2011) pointed out that inversion layers with such coincident minima of $Q_{1}$ and $Q_{2}$ can be related to three candidate mechanisms: 1) a socalled capping inversion layer, which appears at the top of a boundary layer, as supported by Lilly (1968), Betts (1973), Deardorff (1979), and Driedonks and Tennekes (1984); 2) a cloud-top inversion layer generated by radiative cooling; and 3) an inversion layer caused by cloud evaporation. The three candidates are all consistent with the subsidence flow in the middle troposphere. The first candidate is not always applicable because the layer between the levels of 925 and $850 \mathrm{hPa}$ shows a stability anomaly over $0.2 \mathrm{~K} \mathrm{~km}^{-1}$ from $T_{\text {smax }}-0.5$ to +1.5 (Fig. 6), implying the occasional existence of inversion layers. The concurrent development of dual inversion layers is also supported by the result that relatively high stability over $0.4 \mathrm{~K} \mathrm{~km}^{-1}$ can be observed between the 700- and 500-hPa levels in the case of the inversion layers between the levels of 925 and $850 \mathrm{hPa}$ (Fig. 7). The boundary layer is well stirred and mixed with vertical convection and has a homogeneous distribution of potential temperature. Thus, it is difficult to explain all the inversion layers whose thermal factor is vertical advection and $Q_{1}$ by capping inversion layers.

We next use several kinds of diagnosed heating rate in expanded JRA-55 dataset in Fig. 10 to examine candidates 2 and 3. The $Q_{1}$ decrease is best explained by intensified cooling by longwave radiation among all the kinds of heating rate provided by JRA-55 (Fig. 10a). The $Q_{1}$ decreases by 1.26 and $0.73 \mathrm{~K} \mathrm{day}^{-1}$ in the two periods from $T_{\text {smax }}-2.0$ to $T_{\text {smax }}-0.5$ and from $T_{\text {smax }}-0.5$ to $T_{\text {smax }}$, respectively, at $700-\mathrm{hPa}$ level. The longwave radiation intensifies cooling by 0.56 and $0.51 \mathrm{~K} \mathrm{day}^{-1}$ in the same two periods. Intensified longwave cooling in the latter period can explain $70 \%$ of the $Q_{1}$ decrease. On the other hand, the intensified longwave cooling can explain only $44 \%$ of the $Q_{1}$ decrease in the former period. The decrease of large-scale and convective condensation heating explains $25 \%$ and $20 \%$ of the $Q_{1}$ decrease, respectively. The decrease of $Q_{1}$ and longwave radiation heating at the $700-\mathrm{hPa}$ level is accompanied by the decrease of convective condensation heating (Fig. 10b). The intensification of longwave cooling at the $700-\mathrm{hPa}$ level and the weakening of convective 

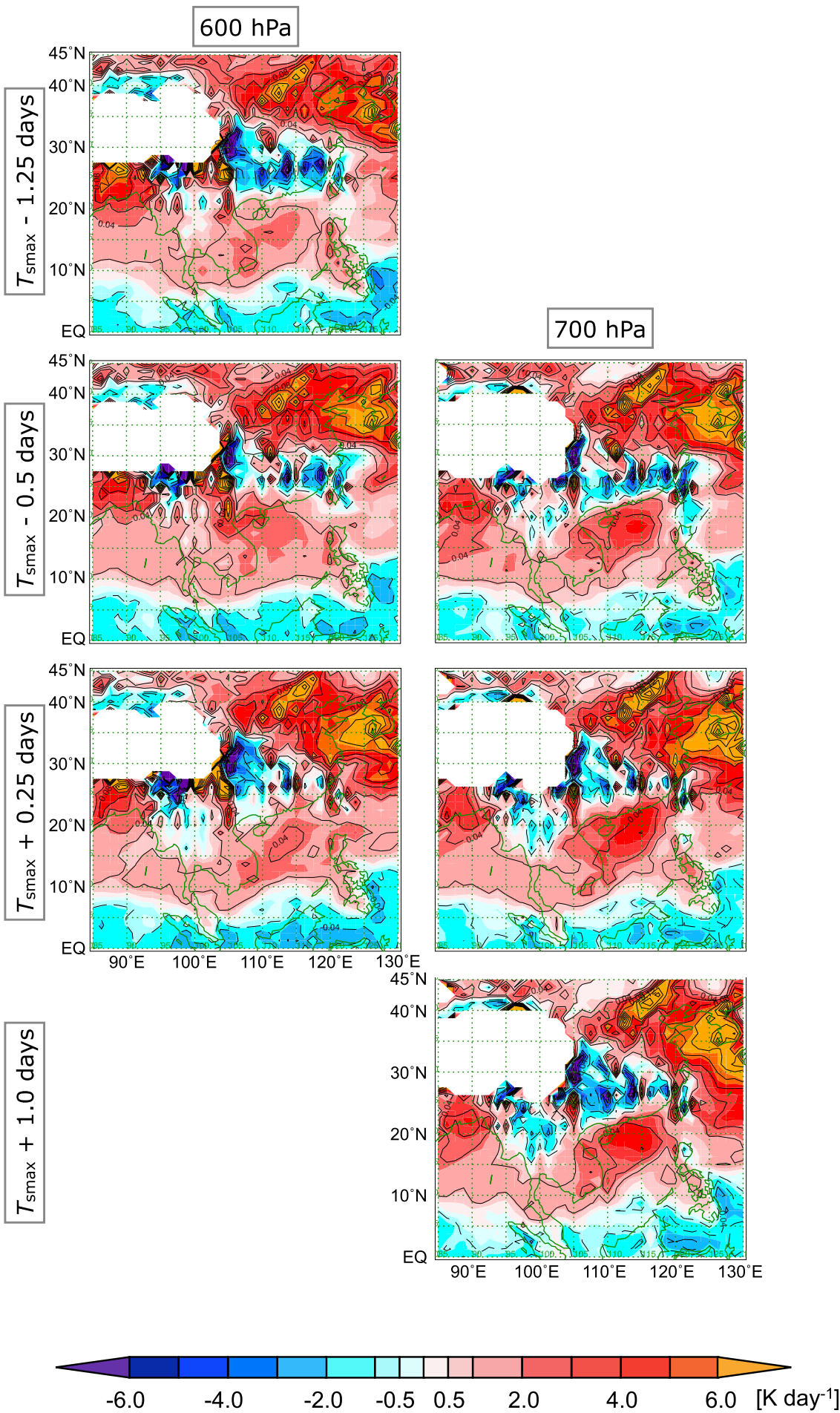

FIG. 8. Composite horizontal maps of vertical advection of potential temperature on the surfaces of (left) 600 and (right) $700 \mathrm{hPa}$ for inversion layers whose dominant thermal factor is vertical advection or $Q_{1}$ appearing in the $700-600-\mathrm{hPa}$ layer in January and February at $21.25^{\circ} \mathrm{N}, 106.25^{\circ} \mathrm{E}\left(\mathrm{K} \mathrm{day}^{-1}\right)$. Shown are (top)-(bottom) $T_{\text {smax }}-1.25,-0.5,+0.25$, and +1.0 days. Black thin contours (interval $0.02 \mathrm{~Pa} \mathrm{~s}^{-1}$ ) show composite vertical velocity; dashed contours show negative (upward velocity) values. The white regions show below-surface or near-surface grids in the model producing the JRA-55 dataset. We excluded a grid with reanalyzed surface pressure less than the pressure value of the analyzed surface minus $30 \mathrm{hPa}$ as a below-surface or near-surface grid from the calculation. 

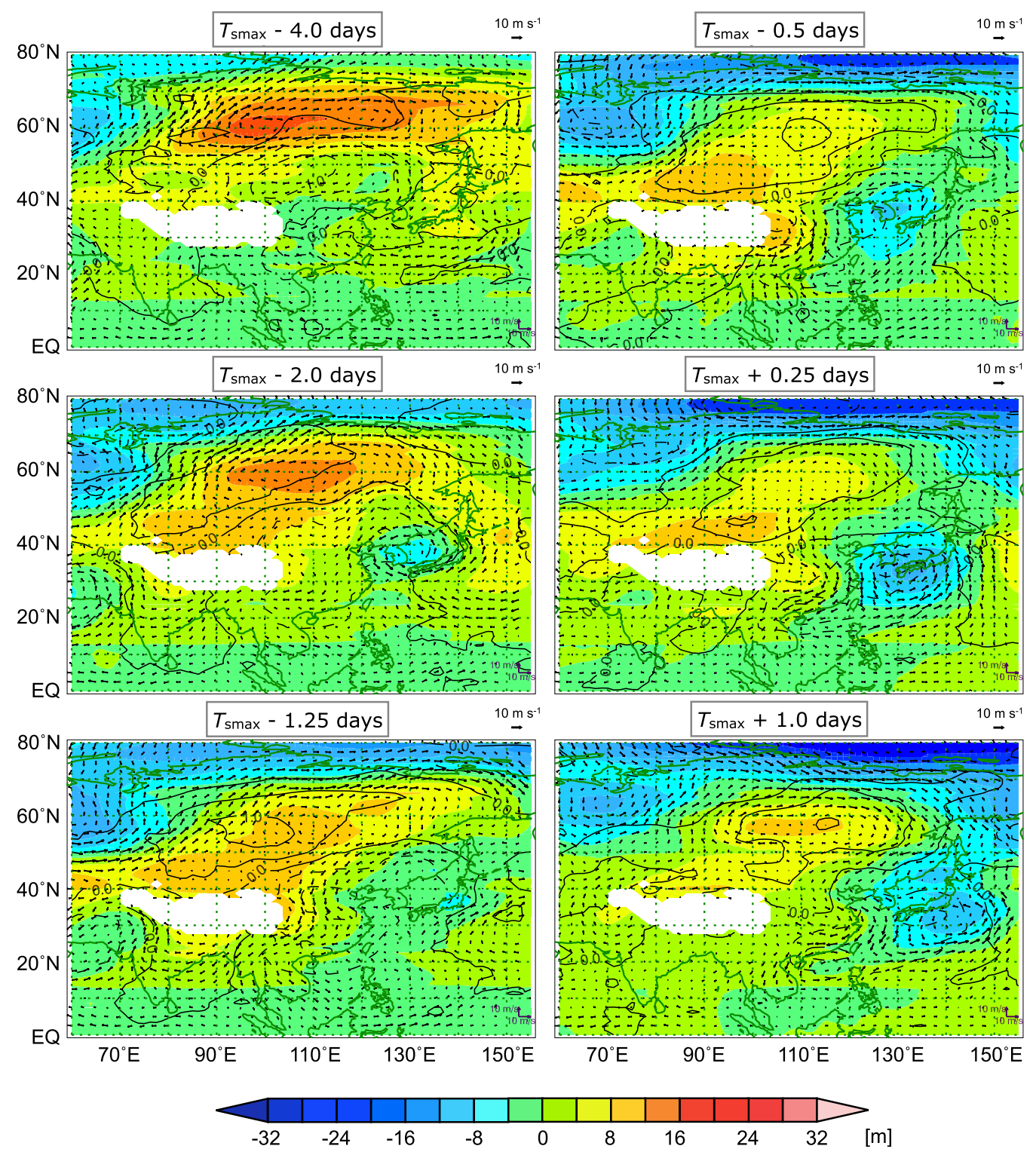

FIG. 9. Horizontal maps of geopotential height (m; color shading) on the 700-hPa surface composited for the same cases as in Fig. 8, with vectors showing winds ( $\mathrm{m} \mathrm{s}^{-1}$; the reference vector in top-right corner of each panel). Black contours show the potential temperature at $0.5-\mathrm{K}$ intervals; dashed contours show negative values. All the values are anomalies from the climatological values. (top left)-(bottom right) Shown are values of $T_{\mathrm{smax}}-3.0$, $-2.0,-1.25,-0.5,+0.25$, and +1.0 days.

condensation heating at the 600 -hPa level are observed over the northeastern edge of Indochina with the horizontal scale of $5^{\circ}$ in latitude/longitude (Fig. 10c). The vertical peak of longwave cooling implies a persistent peak of cloud top at the $700-\mathrm{hPa}$ level. The increase of vertical advection of $\theta$ (Fig. 6b) and the decrease of convective heating after $T_{\text {smax }}-1.5$ indicate the decrease of high clouds and relative increase of cloud-top existence at the $700-\mathrm{hPa}$ level. Figure $10 \mathrm{~d}$ shows time series of the potential temperature tendency, $Q_{1}$, longwave radiation, convective and large-scale condensation heating, vertical advection of $\theta$, and vertical eddy flux divergence of $\theta$ estimated from horizontal and vertical advection subtracted from adiabatic heating rate diagnosed in JRA-55 in the $5^{\circ}$-scale regional mean. Before $T_{\text {smax }}-0.5$, potential temperature tendency decreased with the $Q_{1}$ decrease reflecting the intensification of longwave cooling and the weakening of condensation heating. After $T_{\mathrm{smax}}-0.5$, the $Q_{1}$ more rapidly decreased reflecting the decrease of vertical 
a) long wave radiation

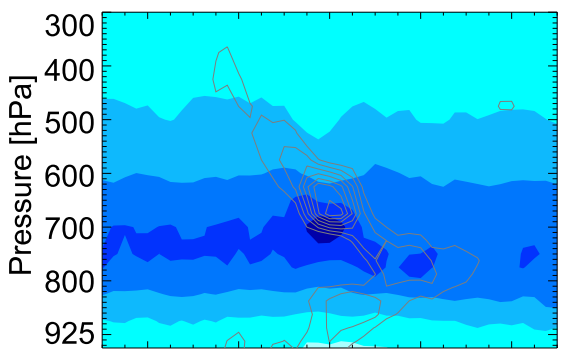

b) convective condensation heating

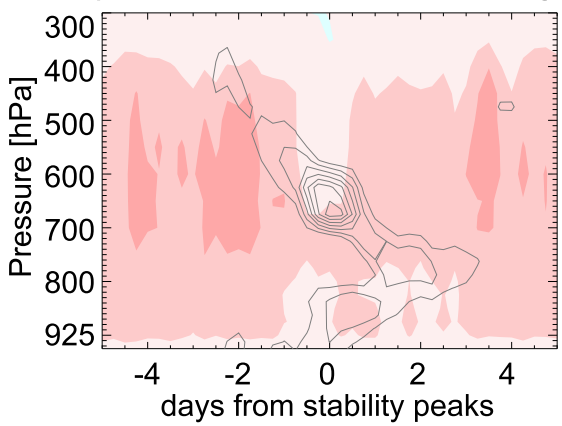

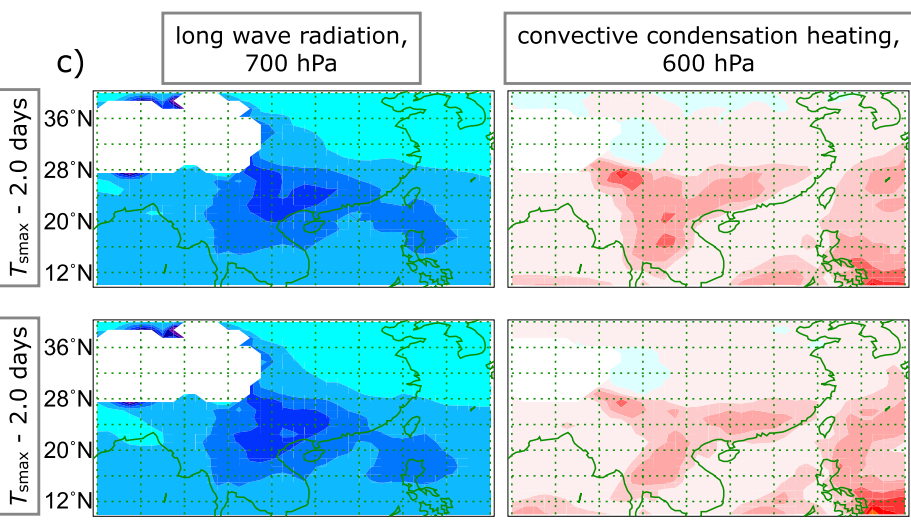
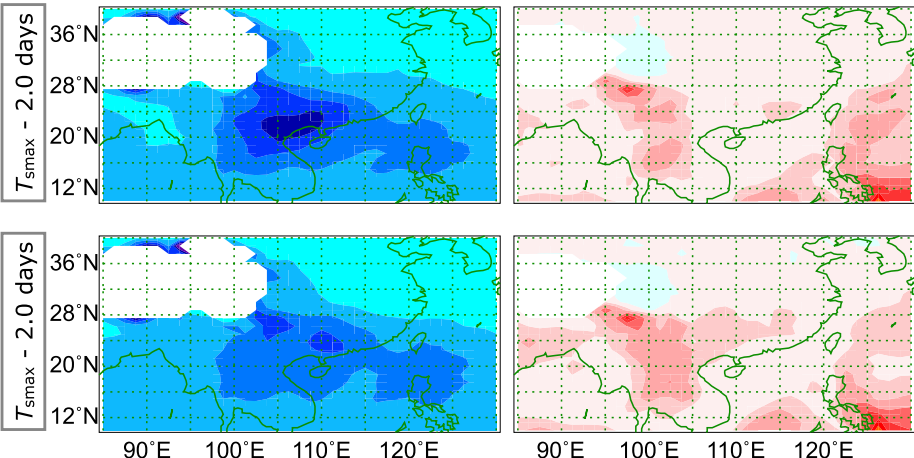

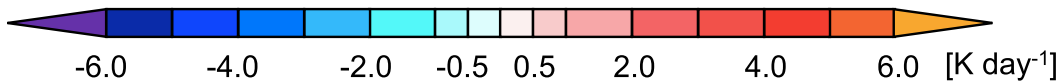

d)

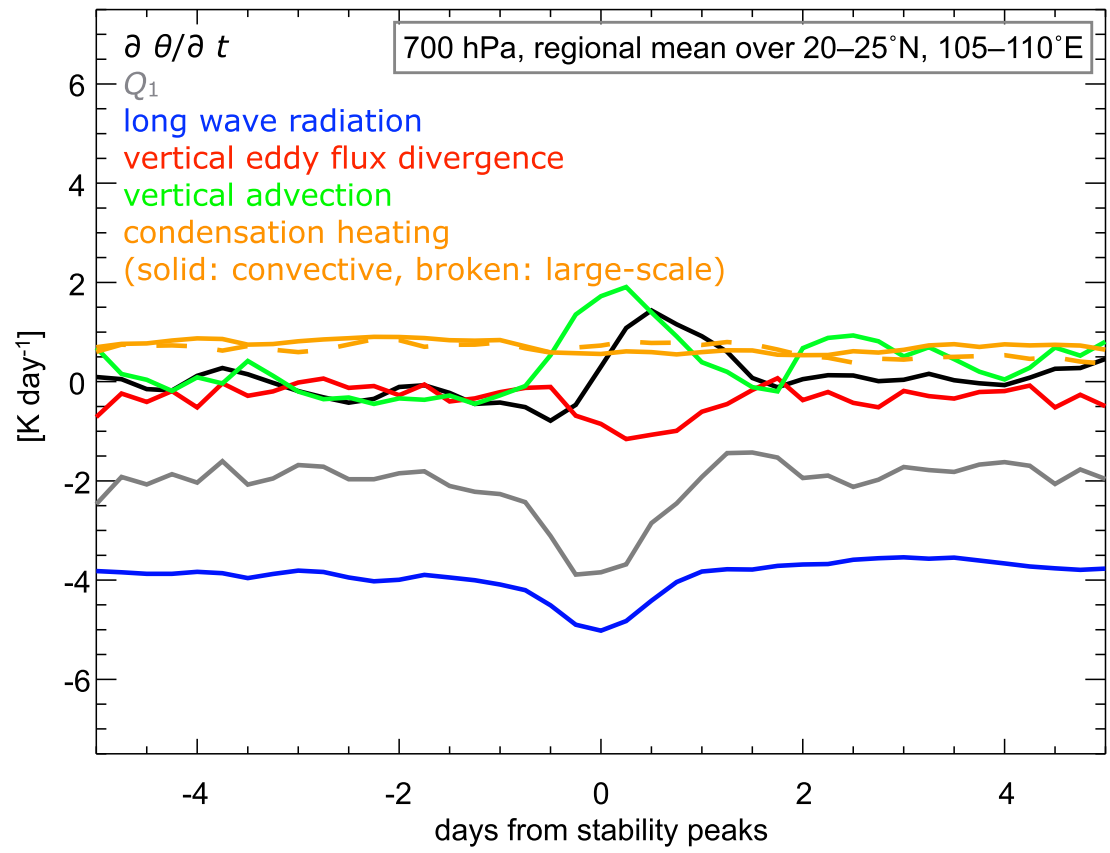

FIG. 10. As in Fig. 3, but for (a) diagnosed longwave radiation and (b) convective condensation heating rate for the same cases as Fig. 8 . (c) Horizontal maps of (left) diagnosed longwave radiation heating rate at $700 \mathrm{hPa}$ and (right) convective condensation heating rate at $600 \mathrm{hPa}$ composited for the same cases as Fig. 8. The time series in (c) are shown from (top) $T_{\text {smax }}-2.0$ at 1-day intervals. (d) Time series of the $\theta$ tendency (black), $Q_{1}$ (gray), vertical advection (green), longwave radiation heating rate (blue), vertical eddy flux divergence (red), and convective (solid orange line) and large-scale (dashed orange line) condensation heating rate at $700 \mathrm{hPa}$ in the regional mean over $20^{\circ}-25^{\circ} \mathrm{N}, 105^{\circ}-110^{\circ} \mathrm{E}$ composited for the same cases as Fig. 8. The composite is calculated over 10 days centered on the time of maximum stability in the 700-600-hPa layer in the inversion layer events. For (a)-(d), all the values are in $\mathrm{K} \mathrm{day}^{-1}$. The white regions in (a)-(c) show underground or near-surface grids as in Fig. 8. 
eddy flux divergence and the continuing intensification of longwave cooling and weakening of condensation heating; however, the potential temperature tendency increases as a result of the rapid increase of vertical advection. The cooling intensification by longwave radiation at $700 \mathrm{hPa}$ implies the inversion layers' development of candidate 2 . On the other hand, there are no negative values indicating cloud evaporation at the 700 -hPa level in both the convective (Fig. 10b) and large-scale (not shown) condensation heating; therefore, candidate 3 can be denied at least the level of the $100-\mathrm{km}$-scale horizontal resolution of the model deriving the JRA-55 dataset.

The above results on the height, wind, temperature fields and the heating rate distributions can be connected with the development processes of inversion layers whose thermal factor is vertical advection or $Q_{1}$ in the layer between the levels of 700 and $600 \mathrm{hPa}$ as follows. A small-scale high pressure separated from the high in the northern foot of the Tibetan Plateau moves southward at the northeastern edge of the plateau. The high pressure introduces strong descent centered in the middle troposphere that is responsible for vertically differentiated subsidence heating, and consequently, the inversion layers appear. The southward movement and rapid decay of the high are reflected in the development and decay of inversion layers over a short period. The processes in the lower levels of the inversion layers can be explained well by cloud-top radiative cooling and partly by a so-called capping inversion; however, cloud evaporation is denied at least on the $100-\mathrm{km}$ horizontal scale. It is possible that these processes are intermingled within the inversion layer events whose thermal factor is vertical advection or $Q_{1}$, although these events basically appear in the subsidence flow.

\section{b. Inversion layers whose thermal factors are horizontal advection in the layer between the levels of 700 and $600 \mathrm{hPa}$}

Here we examine the composite fields for the inversion layers whose thermal factors are horizontal advection of $\theta$ in the layer between the levels of 700 and $600 \mathrm{hPa}$ in January and February. The most important feature in this case is the strong positive horizontal advection between the 600- and 500-hPa levels in the time-height cross-section analysis (Figs. 3 and 4). Neither vertical advection nor $Q_{1}$ have a clear vertical structure that would explain an upper increase and lower decrease of $\theta$ responsible for inversion layer development. The strong positive horizontal advection roughly explains the increase of $\theta$ at the 600-hPa level.

Figure 11 shows horizontal maps of $\theta$ and its horizontal advection. Strong positive horizontal advection protrudes from the north more clearly at $T_{\text {smax }}-1.5$ and $T_{\text {smax }}-0.5$ than at $T_{\text {smax }}-3.0$ and $T_{\text {smax }}+0.5$. The strong positive advection mainly results from zonal advection at $T_{\text {smax }}-0.5$. A warm $\theta$ anomaly is located over western Indochina, with northward curved contours. The warm region originates in the west; it is centered over the Indian subcontinent at $T_{\mathrm{smax}}-3.0$ and moves eastward to reach Bengal at $T_{\mathrm{smax}}-1.5$ and Indochina at $T_{\text {smax }}-0.5$. The eastward movement of the warm region causes an increase in the zonal $\theta$ gradient over the northwestern coast of the South China Sea, and consequently that increases the horizontal advection. The warm region continues to move eastward and reaches the northwestern coastal region of the South China Sea to reduce the temperature gradient and weaken the positive horizontal advection at $T_{\mathrm{smax}}+0.5$. On the 700hPa surface, westerly winds dominate over the northwestern coast of the South China Sea, $\theta$ contours are nearly parallel to the latitude lines throughout the period of analysis, and the horizontal advection is modest compared with that on the 600-hPa surface.

We next examine the composited fields of geopotential height and $\theta$ anomalies (Fig. 12). At the time of maximum stability, the northwestern coast of the South China Sea is covered by the warm anomaly region at $600 \mathrm{hPa}$ expanding over South and Southeast Asia, while it is covered by the cold anomaly region at $700 \mathrm{hPa}$ locally expanding over the northern part of the South China Sea. There are no prominent features in the geopotential height fields over the subtropical region on these levels. Moreover, a high geopotential height region can be recognized over the Bengal region and western Indochina on the $500-\mathrm{hPa}$ surface. The high geopotential height region is prominent on the higher surfaces and clearest on the $150-\mathrm{hPa}$ surface where it coincides with a cold anomaly region. Figure 12 (right) also shows latitude-height cross sections of geopotential height and $\theta$ anomalies averaged between $20^{\circ}$ and $40^{\circ} \mathrm{N}$. A warm anomaly region extends vertically, centered around $500 \mathrm{hPa}$ over Southeast Asia between $90^{\circ}$ and $110^{\circ} \mathrm{E}$ at the time of the stability maximum. This warm region expands below the 250-hPa level, while a cold anomaly region can be seen over the 200-hPa level, consistent with the map of the 150-hPa surface. A high geopotential height region centered at $150 \mathrm{hPa}$ overlays the warm region. Similar and opposite vertical patterns can be seen with a wavelike structure in the zonal direction. The vertical structure of the opposite pattern can be seen around $70^{\circ}$ and $125^{\circ} \mathrm{E}$, with cold anomaly areas centered at 400 and $300 \mathrm{hPa}$, respectively, and warm areas centered at $150 \mathrm{hPa}$. Additionally, low geopotential height anomaly areas are between the cold and warm areas. The pattern appears over the Pacific Ocean at $150^{\circ} \mathrm{E}$ with different altitudes from those 


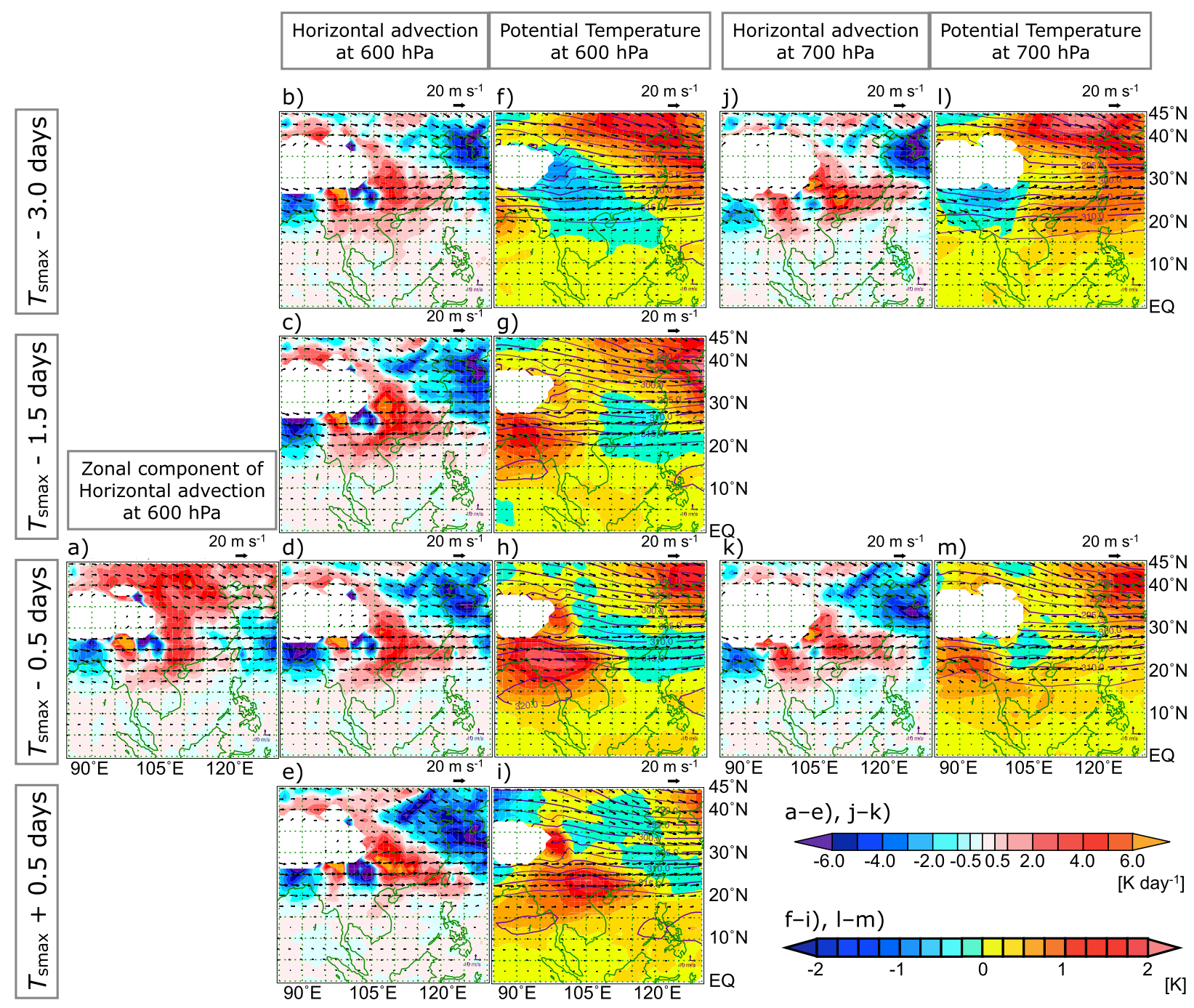

FIG. 11. Composite map of (b)-(e) horizontal advection of potential temperature (K day $\left.{ }^{-1}\right)$ and (f)-(h) potential temperature anomaly (K) with respect to the climatological values at $600 \mathrm{hPa}$ for inversion layers whose dominant thermal factor is horizontal advection appearing in the $700-600-\mathrm{hPa}$ layer in January and February at $21.25^{\circ} \mathrm{N}, 106.25^{\circ} \mathrm{E}$, at $T_{\mathrm{smax}}-3.0,-1.5,-0.5$, and +0.5 days. (a) As in (d), but for the zonal component; (j),(k) as in (b),(d), but at $700 \mathrm{hPa}$; and (l),(m) as in (f),(h), but for $700 \mathrm{hPa}$. Vectors show horizontal wind (reference vector in top-right corner of each panel) and contours in the panels of potential temperature show raw potential temperature. The white regions show underground or near-surface grids as in Fig. 8.

over Southeast Asia, but with a common pattern (moving upward) of a warm area, a high geopotential height area, and a cold area. A zonal train of high- and low-pressure regions moves eastward with a velocity of about $8^{\circ}$ longitude per day and a wavelength of about $50^{\circ}$ longitude. Such a wavelike structure of synoptic-scale disturbances has been investigated by many studies (e.g., Simmons and Hoskins 1979; Chang and Yu 1999; Nakamura and Sampe 2002) in the upper troposphere in the winter. The train of high and low pressures observed in our study has about the same propagation velocity and wavelength as those in these former studies over the eastern side of the Asian continent.

\section{c. Background fields of low stable layers}

Background phenomena are examined for the inversion layers in the layer between the levels of 925 and $850 \mathrm{hPa}$ using composite analysis in this subsection. Figure 13 shows composited horizontal advection of $\theta$ and wind fields on the 925 - and $850-\mathrm{hPa}$ surfaces. At $T_{\text {smax }}-0.75$, when the temperature decreases and negative horizontal advection reaches its maximum at $925 \mathrm{hPa}$ near Hanoi at the gridpoint $21.25^{\circ} \mathrm{N}, 106.25^{\circ} \mathrm{E}$ (Fig. 7), there is a negative horizontal advection zone with northeasterly wind along the northern coast of the 

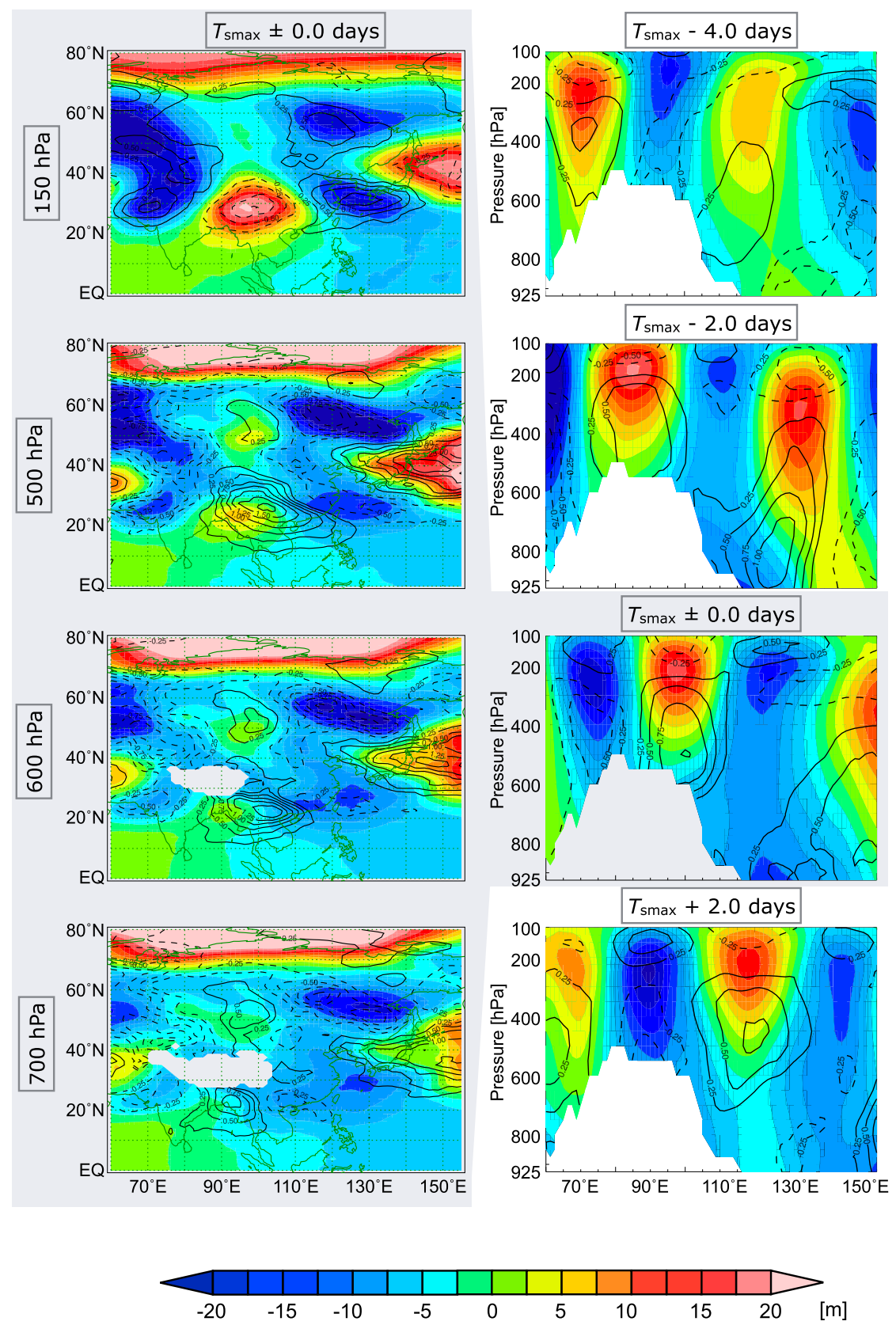

FIG. 12. Horizontal maps and latitude-height cross sections of geopotential height ( $\mathrm{m}$; color shading) and potential temperature $\theta(\mathrm{K}$; contours) anomalies with respect to the climatological values for the same case as in Fig. 11. (left) Shown is the vertical distribution of geopotential height and $\theta$ on the (top)-(bottom) 150-, 500-, 600-, and 700-hPa surfaces. (right) Shown are the time series of geopotential height and $\theta$ from (top) $T_{\mathrm{smax}}-4.0$ to (bottom) +2.0 days at 2 -day intervals. The panels showing $T_{\text {smax }} \pm 0.0$ days are on a gray background. The white regions show underground or near-surface grids as in Fig. 8. We used common colors and contour styles for both panels.

South China Sea. The zone extends from the East China Sea westward over East Asia as a narrow band, with horizontal advection in the center of this band being less than $-5 \mathrm{~K} \mathrm{day}^{-1}$. The grid point near Hanoi is located on the southwestern edge of the zone and has horizontal advection values of about $-2 \mathrm{Kday}^{-1}$. In contrast, there is a region of positive horizontal advection over the northwestern coast of the South China Sea with 

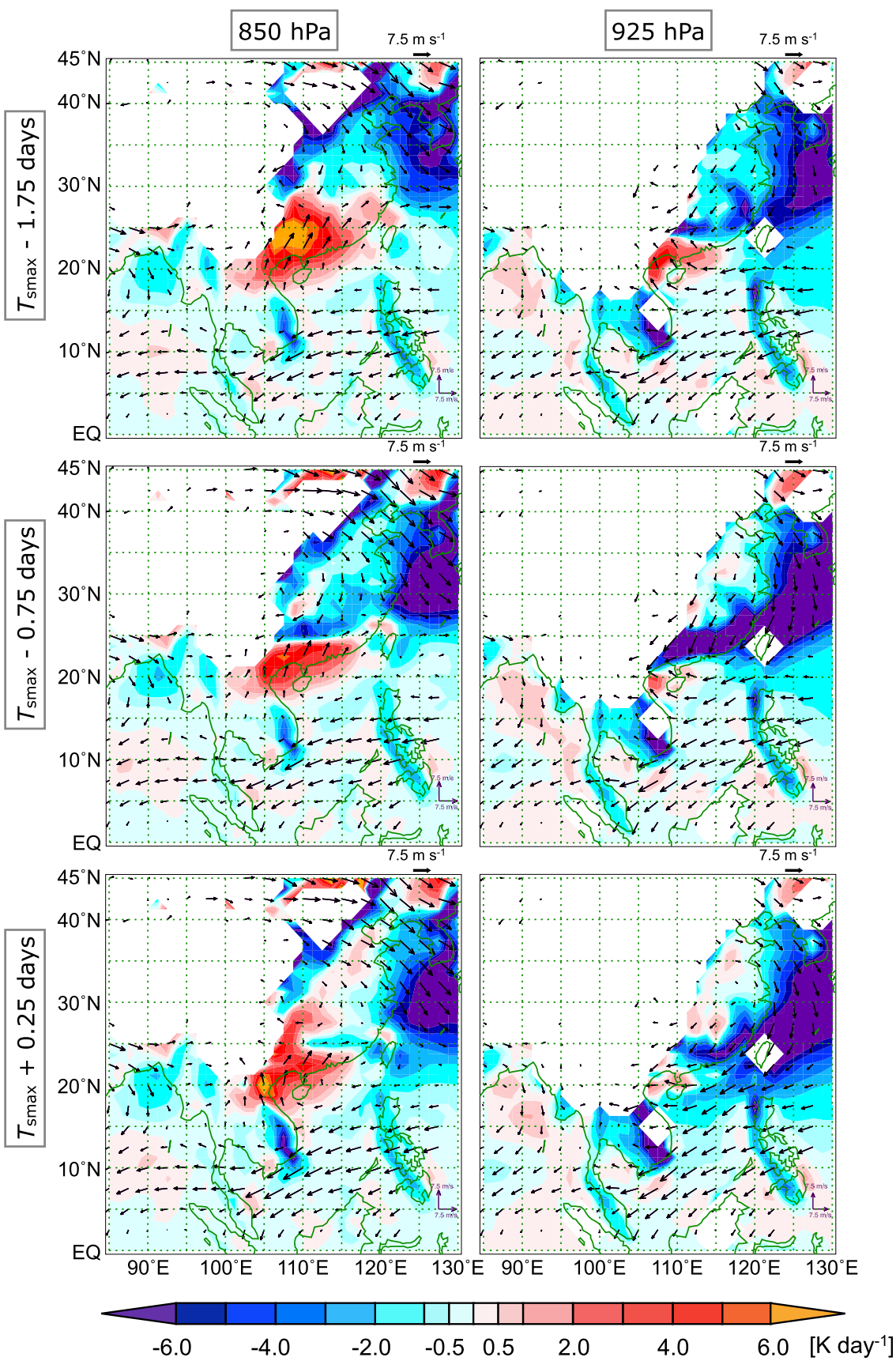

FIG. 13. Composite map of the horizontal advection of potential temperature $\left(\mathrm{K} \mathrm{day}^{-1}\right)$ at (left) 850 and (right) $925 \mathrm{hPa}$ for inversion layers in the layer between the 925- and 850$\mathrm{hPa}$ levels from January to March at $21.25^{\circ} \mathrm{N}, 106.25^{\circ} \mathrm{E}$ from (top) $T_{\text {smax }}-1.75$ to (bottom) +0.25 days at 1 -day intervals. Vectors show horizontal wind (reference vector in top-right corner of each panel). The white regions show underground or near-surface grids as in Fig. 8.

southwesterly winds slightly south of the zone of negative horizontal advection. The negative horizontal advection region extends upward over the East China Sea. The positive horizontal advection region appears only over the northwestern coast of the South China
Sea on the $850-\mathrm{hPa}$ surface. The vertical structure of the horizontal advection is similar to that of a cold front in the midlatitude zone over this region. The positive and negative horizontal advection on the 850and $925-\mathrm{hPa}$ surfaces, respectively, are located to the 
north at $T_{\text {smax }}-1.75$ and the cold-front-like structure moves southward. The positive horizontal advection region shrinks and weakens from $T_{\text {smax }}-1.75$ to -0.75 on the $850-\mathrm{hPa}$ surface, while the negative horizontal advection region intensifies from $T_{\mathrm{smax}}-1.75$ to -0.75 at $925 \mathrm{hPa}$. The frontlike structure breaks down with a rapid decay of the negative horizontal advection on the 925$\mathrm{hPa}$ surface. However, the region of positive horizontal advection intensifies again at $T_{\mathrm{smax}}+0.25$. The results indicate that the cold-front-like structure from the north is related to the stable layer between the levels of 925 and $850 \mathrm{hPa}$.

Composited climatological anomaly fields of pressure and horizontal wind (Fig. 14) are used to investigate a disturbance causing this cold front. At $T_{\mathrm{smax}}-5.0$ and $T_{\text {smax }}-3.0$, Indochina is under the southern edge of a low pressure area with a center located over the eastern foot of the Tibetan Plateau on the 850-hPa surface (Figs. 14a,b). The low pressure area shrinks and high pressure appears over the northeastern foot of the plateau at $T_{\text {smax }}-1.5$ (Fig. 14c). The high pressure appears when another synoptic high pressure area comes from northwestern Eurasia, which is located over the western Siberian Plain at $T_{\text {smax }}-5.0$ and moved southeastward to reach the northern foot of the Altaic Mountains at $T_{\text {smax }}-3.0$. The high pressure located over the northeastern foot of the Tibetan Plateau at $T_{\text {smax }}-1.5$ moves southward and weakens. It reaches the northwestern coast of the South China Sea at $T_{\mathrm{smax}}-0.5$ (Fig. 14d). On the 925-hPa surface, the high pressure and a contrastive lower region southward is clearer than on the 850-hPa surface at this time (Fig. 14h). The stronger meridional gradient of the geopotential height corresponds to stronger northeasterly wind at $925 \mathrm{hPa}$. Figure 14 shows anomaly fields from the climatological values; therefore, the wind direction at $850 \mathrm{hPa}$ at $T_{\text {smax }}-0.75$ over the northwestern coast of the South China Sea seen in Fig. 13 reflects the climatological southwesterly wind and weak anomaly wind shown in Fig. 14. On the other hand, the speed of the northeasterly wind in Fig. 13 is comparable with that in Fig. 14 at $925 \mathrm{hPa}$; thus, a subseasonal variation brings the northwesterly wind advecting cold air. At $T_{\text {smax }}+0.5$, the high pressure weakens considerably on the $850-\mathrm{hPa}$ surface, while on the $925-\mathrm{hPa}$ surface there is a distinct high geopotential height region over mainland China and a region of northeasterly wind over the SCS and its coast (Figs. 14e,i). The high pressure remains over the southeastern foot of the plateau at $T_{\text {smax }}+1.5$ and $T_{\text {smax }}+3.0$, and the northeasterly wind is dominant especially on the $925-\mathrm{hPa}$ surface over the SCS and Indochina (Figs. 14f,g,j,k). A clear cold $\theta$ anomaly is accompanied by the high pressure mentioned above during the migration around the Tibetan Plateau from $T_{\text {smax }}-3.0$ to +1.5 .

In summary, inversion layers in the layer between the 925- and 850-hPa levels may be explained as follows. A high pressure located in northern Eurasia moves eastward and divides into two. One part moves southward along the Tibetan Plateau from its northeastern edge. This high consists of cold air and northerly wind in the lower layer below the 850-hPa level. The combination of high pressure with cold air has the same structure and time evolution as a monsoonal pressure surge (e.g., Compo et al. 1999), which was explained as a coastal Kelvin wave trapped by the plateau in a pioneering numerical study by Nakamura and Doutani (1985). The cold air intrudes under the warm air to the south and forms a structure like a cold front almost along the northwestern coast of the South China Sea with a strong north-south $\theta$ gradient. Over this region, there is negative horizontal advection of $\theta$ with northerly winds at the southern edge of the high pressure at $925 \mathrm{hPa}$, while at $850 \mathrm{hPa}$ there is positive horizontal advection with southerly winds in the southern region outside the high. The lower level is cooled by the negative horizontal advection from the north, while the upper level is warmed by the positive horizontal advection from the south. The vertically differentiated $\theta$ tendency contributed by horizontal advection causes the inversion layer development between the 925- and 850-hPa levels.

We add that the behavior of the high pressure resembles that described for the inversion layers in the layer between the 700- and 600-hPa levels whose dominant thermal factors are vertical advection or $Q_{1}$, except with slower propagation and a more northward path for the high propagating eastward. These types of inversion layer events coincide as mentioned in section $4 a$. These results indicate that the high pressure at the low level from the north sometimes caused inversion layers both at the low and high levels. On the other hand, high stability cannot be observed in the layer between the levels of 925 and $850 \mathrm{hPa}$ in the case of inversion layers in the layer between the levels of 700 and $600 \mathrm{hPa}$ whose dominant thermal factor is horizontal advection of $\theta$ (Fig. 5).

\section{d. Comparison with inversion layers mechanisms over the inland of Indochina}

Last we will give a comparison in mechanisms with inversion layers over the inland of Indochina studied in Nodzu et al. (2011).

Two points are obtained on the similarity in the present study. One is that the lower inversion layers are caused by cold surges accompanied by southward-propagating highs 

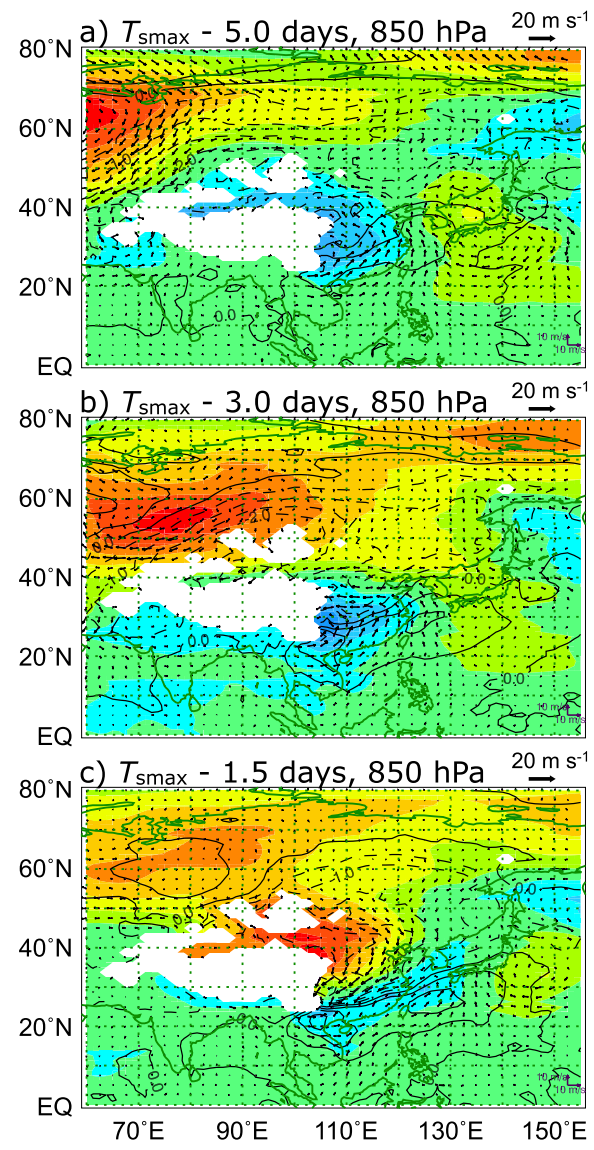

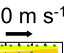
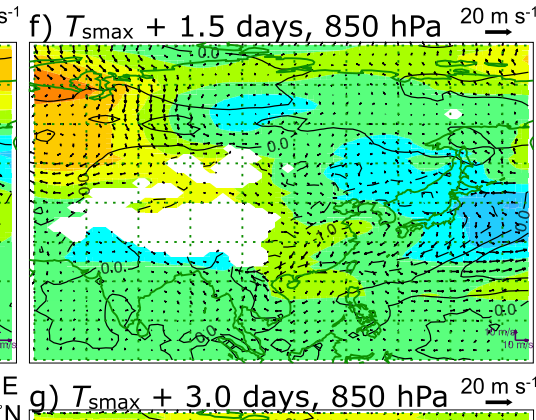

$80^{\circ} \mathrm{N}$
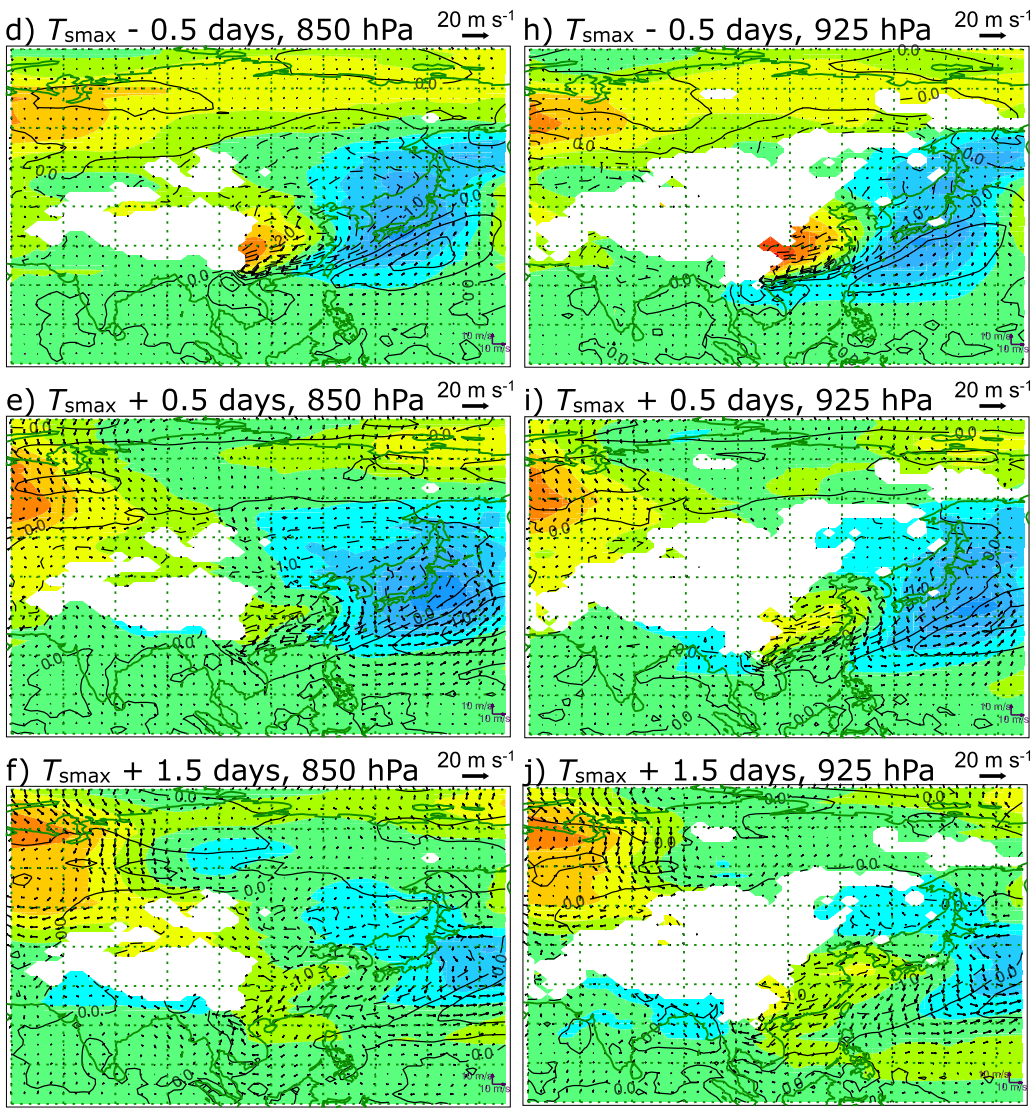

k) $T_{\text {smax }}+3.0$ days, $925 \mathrm{hPa}{ }^{20 \mathrm{~m} \mathrm{~s}^{-1}}$
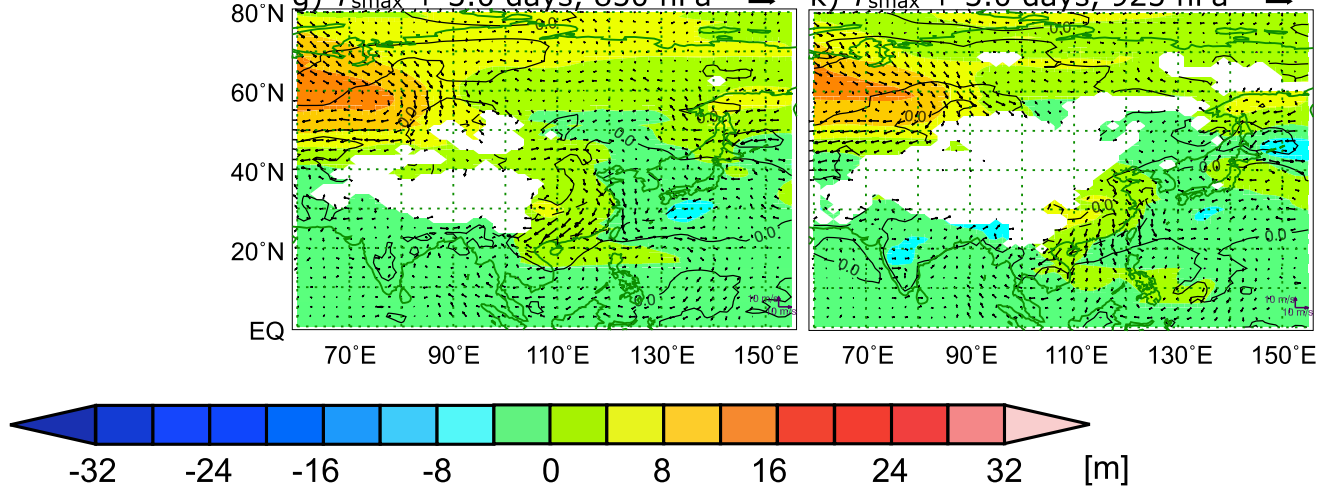

FIG. 14. As in Fig. 8, but at (a)-(g) 850 and (h)-(k) $925 \mathrm{hPa}$ for inversion layers in the layer between 925 and $850 \mathrm{hPa}$ from January to March at $21.25^{\circ} \mathrm{N}, 106.25^{\circ} \mathrm{E}$ for $T_{\text {smax }}(\mathrm{a})-5.0$, (b) -3.0, (c) $-1.5,(\mathrm{~d}),(\mathrm{h})-0.5$, (e), (i) $+0.5,(\mathrm{f}),(\mathrm{j})+1.5$, and (g), (k) +3 days.

as advective inversion layers. We note that the layer where lower inversion layers frequently appear is lower in the northwest coast of the South China Sea than that in the inland. This will reflect the difference in the upper surface height of the cold surges in the two regions. We guess that the difference can be simply related with the lifting brought by the Annan Mountains dividing two regions. The other point of the similarity is that the development of inversion layers in the layer between the levels of 700 and $600 \mathrm{hPa}$ whose dominant thermal factors are vertical advection of $\theta$ or $Q_{1}$ are related with negative $Q_{1}$ at the lower level. In the present study, we advanced the understanding that longwave cooling at the cloud top can be strongly related with such a type of inversion layer development by using diagnosed heating rate in JRA55. On the other hand, the analysis implies that all the inversion layers of these types cannot always be explained as a capping inversion on the top of the boundary layer. Moreover, it is difficult to explain them by the cloud evaporation at least on the scale of 
$100 \mathrm{~km}$. The upper-layer subsidence heating was not clearly recognized in the case of the inland. This result implies the difference of subsidence flow within the highs in the different regions.

We examine also the inversion layers in the layer between the levels of 700 and $600 \mathrm{hPa}$ whose dominant thermal factors are horizontal advection of $\theta$ due to their substantial contribution to inversion layer appearance over the northwestern coast of the South China Sea in the present study. The results from this analysis are related with the eastward-propagating wavelike structure in the upper troposphere with a synoptic scale.

\section{Conclusions}

The processes generating dual vertical inversion layers over the northwestern coast of the South China Sea in the latter half of the boreal winter were investigated using the 6-hourly JRA-55 data for $29 \mathrm{yr}$ from 1979 to 2007. Two types of analysis were carried out: a comparison of the thermal terms in the thermal budget equation [Eq. (2)], relating them to the development of inversion layers, and an investigation of the mechanisms responsible for changes in temperature related to inversion layer development. The layers between the 700- and 600-hPa levels and 925- and 850-hPa levels were selected for analysis in the present study based on the climatological frequency of inversion layers in the season-height cross section.

Results from the analysis of the inversion layers in the layer between the levels of 700 and $600 \mathrm{hPa}$ are as follows:

- No overwhelming dominant thermal factors exist for inversion layer development.

- Inversion layers whose dominant thermal factors are vertical advection of $\theta$ or $Q_{1}$ are characterized by a deep layer of strong positive vertical advection of $\theta$ above the $600-\mathrm{hPa}$ level during the inversion layer development.

- The vertical advection heating is caused by subsidence in the middle troposphere accompanied by high pressure taking a clockwise path along the northern and eastern feet of the Tibetan Plateau.

- Inversion layers whose dominant thermal factors are horizontal advection of $\theta$ are characterized by strong positive horizontal advection between the 600and $500-\mathrm{hPa}$ levels above the inversion layer development.

- The positive horizontal advection occurs when the eastward-propagating region of high temperature passes over the northwestern coast of the South China Sea. The high temperature region is accompanied by a high pressure that is a part of the zonal wavelike structure in the upper troposphere.

Results from the analysis of the inversion layers in the layer between the levels of 925 and $850 \mathrm{hPa}$ are outlined as follows:

- Temperature decrease below the inversion layer is related to negative horizontal advection of $\theta$ at $925 \mathrm{hPa}$ during the inversion layer development.

- The negative horizontal advection appears when the zonally elongated negative horizontal advection region reaches the northwestern coast of the South China Sea on the 925-hPa surface. This negative horizontal advection is located under the positive horizontal advection region on the $850-\mathrm{hPa}$ surface around the northwestern coast of the South China Sea.

- The zonally elongated negative horizontal advection region corresponds to the strong outflow of cold air at the southern edge of the high pressure. The high pressure moves along the northern and eastern feet of the Tibetan Plateau like the high in the cases of inversion layers whose dominant thermal factors are vertical advection of $\theta$ or $Q_{1}$ in the layer between the 700- and 600-hPa levels.

- The results indicate that some of the inversion layers between the 925- and 850-hPa levels occur concurrently with the inversion layers whose dominant thermal factors are vertical advection of $\theta$ or $Q_{1}$ in the layer between the 700- and 600-hPa levels.

The above results reveal that the frequent appearance of inversion layers at the two levels around 1.5 and $4 \mathrm{~km}$ shown by Nodzu et al. (2006) can be explained by a combination of the following types of inversion layers: 1) advective inversion layers on the lower border of warm air in the middle troposphere accompanied by eastward-propagating high pressure in the upper troposphere, 2) subsidence inversion layers in the middle troposphere partly related with cloud-top radiative cooling and boundary layer over a southward propagating high pressure in the lower troposphere, and 3) inversion layers with a cold-front-like structure on the southern edge of the southward-propagating high. Structures 2 and 3 sometimes coincide. Therefore, the climatological picture of the dual inversion layer is clarified by the combined influence of potential temperature advection caused by migratory high pressures at different levels. These conclusions are consistent with that obtained by using the other reanalysis dataset JRA-25.

Our results imply that some of the inversion layers whose dominant thermal factors are vertical advection of $\theta$ or $Q_{1}$ in the layer between the $700-$ and $600-\mathrm{hPa}$ 
levels coincide with inversion layers in the layer between the 925- and $850-\mathrm{hPa}$ levels. This coincidence is interesting and crucial to advance our understandings of the structure of a pressure surge in the Asian winter monsoon. The present study related the inversion layers and the structure of the high pressure regions in the upper and lower troposphere. These highs keep a similar structure of temperature and wind before arriving over the northwestern coast of the South China Sea, so it is natural to think that the stability also has a similar structure despite some transformation. This is also an interesting topic. We assumed the vertical velocity in the reanalysis data to be valid for thermal budget analysis above the 700-hPa level in the free atmosphere. The vertical velocity should be compared with that obtained from sounding data in order to confirm its validity and expand the application range into the boundary layer. The present study also revealed the temperature and flow conditions in the middle and lower troposphere in connection with tropospheric inversion layers. The added knowledge of the inversion layers and the related atmospheric conditions will contribute to a better understanding of chemical and transport processes.

Acknowledgments. We thank Prof. Manabu D. Yamanaka for useful advice and encouragement, Dr. Tomoshige Inoue and Mr. Souya Watanabe for discussion of the time scale of inversion layer events and its relationship with the synoptic disturbances, Prof. Jun-Ichi Hamada and Mr. Masatoshi Kikuchi for discussion on the influence of aerosol and ozone on the thermal budget, Dr. Hiroshi Takahashi for comments on the relationship between the transport of ozone and the inversion layers and the appropriate use of reanalysis data, Prof. Hideo Takahashi for comments on the relationship between the different types of inversion layers and their background, Dr. Hisahiro Takashima for comments on the possibility of a dynamical mechanism, and Dr. Takashi Sekiya for comments on the transport of ozone. The constructive comments of the two anonymous reviewers and the editor, Hisashi Nakamura, led to significant improvements in the manuscript. This study was supported by the Science and Technology Research Partnership for Sustainable Development of the Japan International Cooperation Agency and the Japan Science and Technology Agency and the Japan Aerospace Exploration Agency Precipitation Measuring Mission.

\section{REFERENCES}

Betts, A. K., 1973: Non-precipitating cumulus convection and its parameterization. Quart. J. Roy. Meteor. Soc., 99, 178-196, https://doi.org/10.1002/qj.49709941915.
Boersma, K. F., and Coauthors, 2011: An improved tropospheric $\mathrm{NO}_{2}$ column retrieval algorithm for the Ozone Monitoring Instrument. Atmos. Meas. Tech., 4, 1905-1928, https://doi.org/ 10.5194/amt-4-1905-2011.

Chang, E. K. M., and D. B. Yu, 1999: Characteristics of wave packets in the upper troposphere. Part I: Northern Hemisphere winter. J. Atmos. Sci., 56, 1708-1728, https://doi.org/ 10.1175/1520-0469(1999)056<1708:COWPIT>2.0.CO;2.

Compo, G. P., G. N. Kiladis, and P. J. Webster, 1999: The horizontal and vertical structure of East Asian winter monsoon pressure surges. Quart. J. Roy. Meteor. Soc., 125, 29-54, https://doi.org/10.1002/qj.49712555304.

Deardorff, J. W., 1979: Prediction of convective mixed-layer entrainment for realistic capping inversion structure. J. Atmos. Sci., 36, 424-436, https://doi.org/10.1175/1520-0469(1979)036<0424: POCMLE $>2.0 . \mathrm{CO} ; 2$.

Driedonks, A. G. M., and H. Tennekes, 1984: Entrainment effects in the well-mixed atmospheric boundary layer. Bound.-Layer Meteor., 30, 75-105, https://doi.org/10.1007/ BF00121950.

Fehsenfeld, F. C., and Coauthors, 1983: A study of ozone in the Colorado mountains. J. Atmos. Chem., 1, 87-105, https:// doi.org/10.1007/BF00113981.

Fukao, S., and K. Hamazu, 2014: Radar for Meteorological and Atmospheric Observations. Springer, $537 \mathrm{pp}$.

Goto, D., K. Ueda, C. F. Sheng Ng, A. Takami, T. Ariga, K. Matsuhashi, and T. Nakajima, 2016: Estimation of excess mortality due to long-term exposure to PM2.5 in Japan using a high-resolution model for present and future scenarios. Atmos. Environ., 140, 320-332, https://doi.org/10.1016/ j.atmosenv.2016.06.015.

Harada, Y., and Coauthors, 2016: The JRA-55 Reanalysis: Representation of atmospheric circulation and climate variability. J. Meteor. Soc. Japan, 94, 269-302, https://doi.org/10.2151/ jmsj.2016-015.

Johnson, R. H., T. M. Rickenbach, S. A. Rutledge, P. E. Ciesielski, and W. H. Schubert, 1999: Trimodal characteristics of tropical convection. J. Climate, 12, 2397-2418, https://doi.org/10.1175/ 1520-0442(1999)012<2397:TCOTC >2.0.CO;2.

Kanaya, Y., and Coauthors, 2014: Long-term MAX-DOAS network observations of $\mathrm{NO}_{2}$ in Russia and Asia (MADRAS) during 2007-2012: Instrumentation, elucidation of climatology, and comparisons with OMI satellite observations and global model simulations. Atmos. Chem. Phys. 14, 7909-7927, https://doi.org/10.5194/acp-14-7909-2014.

Kobayashi, S., and Coauthors, 2015: The JRA-55 Reanalysis: General specifications and basic characteristics. J. Meteor. Soc. Japan, 93, 5-48, https://doi.org/10.2151/jmsj.2015-001.

Lilly, D. K., 1968: Models of cloud-topped mixed layers under a strong inversion. Quart. J. Roy. Meteor. Soc., 94, 292-309, https://doi.org/10.1002/qj.49709440106.

Müller, H., and C. D. Whiteman, 1988: Breakup of a nocturnal temperature inversion in the Dischma Valley during DISKUS. J. Appl. Meteor., 27, 188-194, https://doi.org/10.1175/ 1520-0450(1988)027<0188:BOANTI>2.0.CO;2.

Nakamura, H., and T. Doutani, 1985: A numerical study on the coastal Kelvin wave features about the cold surge around the Tibetan Plateau. J. Meteor. Soc. Japan, 63, 547-563, https:// doi.org/10.2151/jmsj1965.63.4_547.

_ bances into the North-Pacific subtropical jet core in midwinter. Geophys. Res. Lett., 29, https://doi.org/10.1029/ 2002 GL015535. 
Nakanishi, M., R. Shibuya, J. Ito, and H. Niino, 2014: Large-eddy simulation of a residual layer: Low-level jet, convective rolls, and Kelvin-Helmholtz instability. J. Atmos. Sci., 71, 4473-4491, https://doi.org/10.1175/JAS-D-13-0402.1.

Nodzu, M. I., S.-Y. Ogino, Y. Tachibana, and M. D. Yamanaka, 2006: Climatological description of seasonal variations in lower-tropospheric temperature inversion layers over the Indochina Peninsula. J. Climate, 19, 3307-3319, https://doi.org/ 10.1175/JCLI3792.1.

- _ _ , and M. D. Yamanaka, 2011: Seasonal changes in a vertical thermal structure producing stable lower-troposphere layers over the inland region of the Indochina Peninsula. J. Climate, 24, 3211-3223, https://doi.org/10.1175/ 2010JCLI3871.1.

Ogino, S.-Y., M. Fujiwara, M. Shiotani, F. Hasebe, J. Matsumoto, T. H. T. Hoang, and T. T. T. Nguyen, 2013: Ozone variations over the northern subtropical region revealed by ozonesonde observations in Hanoi. J. Geophys. Res. Atmos., 118, 32453257, https://doi.org/10.1002/jgrd.50348.

Onogi, K., and Coauthors, 2007: The JRA-25 Reanalysis. J. Meteor. Soc. Japan, 85, 369-432, https://doi.org/10.2151/jmsj.85.369.

Simmons, A. J., and B. J. Hoskins, 1979: The downstream and upstream development of unstable baroclinic waves. J. Atmos. Sci., 36, 1239-1254, https://doi.org/10.1175/1520-0469(1979)036<1239: TDAUDO $>2.0 . \mathrm{CO} ; 2$.

Wallace, J., and P. Kanaroglou, 2009: The effect of temperature inversions on ground-level nitrogen dioxide $\left(\mathrm{NO}_{2}\right)$ and fine particulate matter (PM2.5) using temperature profiles from the Atmospheric Infrared Sounder (AIRS). Sci. Total Environ., 407, 5085-5095, https://doi.org/10.1016/j.scitotenv.2009.05.050.

Yanai, M., S. Esbensen, and J. H. Chu, 1973: Determination of bulk properties of tropical cloud clusters from large-scale heat and moisture budgets. J. Atmos. Sci., 30, 611-627, https://doi.org/ 10.1175/1520-0469(1973)030<0611:DOBPOT>2.0.CO;2. 